\title{
Spatiotemporal Dynamics of Functional Clusters of Neurons in the Mouse Motor Cortex during a Voluntary Movement
}

\author{
Riichiro Hira, ${ }^{1,2,4}$ Fuki Ohkubo, ${ }^{1,2,4}$ Katsuya Ozawa, ${ }^{2,4}$ Yoshikazu Isomura, ${ }^{2,6}$ Kazuo Kitamura, ${ }^{2,3,5}$ Masanobu Kano, ${ }^{5}$ \\ Haruo Kasai, ${ }^{4}$ and Masanori Matsuzaki ${ }^{1,2,4}$ \\ ${ }^{1}$ Division of Brain Circuits, National Institute for Basic Biology and the Graduate University of Advanced Studies (Sokendai), Myodaiji, Okazaki 444-8585, \\ Japan, Japan Science and Technology Agency, ${ }^{2}$ CREST and ${ }^{3}$ PRESTO, Saitama 332-0012, Japan, ${ }^{4}$ Laboratory of Structural Physiology, Center for Disease \\ Biology and Integrative Medicine and ${ }^{5}$ Department of Neurophysiology, Graduate School of Medicine, University of Tokyo, Tokyo 113-0033, Japan, and \\ ${ }^{6}$ Brain Science Institute, Tamagawa University, Machida, Tokyo 194-8610, Japan
}

Functional clustering of neurons is frequently observed in the motor cortex. However, it is unknown if, when, and how fine-scale $(<100$ $\mu \mathrm{m}$ ) functional clusters form relative to voluntary forelimb movements. In addition, the implications of clustering remain unclear. To address these issues, we conducted two-photon calcium imaging of mouse layer $2 / 3$ motor cortex during a self-initiated lever-pull task. In the imaging session after 8-9 days of training, head-restrained mice had to pull a lever for $\sim 600 \mathrm{~ms}$ to receive a water drop, and then had to wait for $>3 \mathrm{~s}$ to pull it again. We found two types of task-related cells in the mice: cells whose peak activities occurred during lever pulls (pull cells) and cells whose peak activities occurred after the end of lever pulls. The activity of pull cells was strongly associated with lever-pull duration. In $\sim 40 \%$ of imaged fields, functional clusterings were temporally detected during the lever pulls. Spatially, there were $\sim 70$ - $\mu \mathrm{m}$-scale clusters that consisted of more than four pull cells in $\sim 50 \%$ of the fields. Ensemble and individual activities of pull cells within the cluster more accurately predicted lever movement trajectories than activities of pull cells outside the cluster. This was likely because clustered pull cells were more often active in the individual trials than pull cells outside the cluster. This higher fidelity of activity was related to higher trial-to-trial correlations of activities of pairs within the cluster. We propose that strong recurrent network clusters may represent the execution of voluntary movements.

\section{Introduction}

The clustering of neurons that are related to the same movement, regardless of whether it is a simple or complex movement, is a hallmark characteristic of motor cortex organization (Asanuma and Rosén, 1972; Graziano et al., 2002; Dombeck et al., 2009). What specific aspects of these neurons are clustered? The prefer-

\footnotetext{
Received May 24, 2012; revised 0ct. 15, 2012; accepted Nov. 10, 2012.

Author contributions: R.H., Y.I., K.K., and M.M. designed research; R.H., F.O., and K.O. performed research; Y.I., K.K., M.K., and H.K. contributed unpublished reagents/analytic tools; R.H., F.O., and K.O. analyzed data; R.H. and M.M. wrote the paper.

This work was supported by Grants-in-Aid for Young Scientists (No. 19680020 to M.M. and 22680031 to K.K.), by Scientific Research on Innovative Areas "Mesoscopic Neurocircuitry" (No. 22115005 to M.M. and 23115504 to K.K.) and "Neural Creativity for Communication" (No. 22120520 to Y.I.), by Challenging Exploratory Research (No. 22650083 to K.K.), by Scientific Research (No. 23300148 to M.M. and 21220006 to M.K.), by JSPS Fellows (No. 22136 to R.H.), by Specially Promoted Research Areas (No. 2000009 to H.K.), by the Global COE Program (Integrative Life Science based on the study of Biosignaling Mechanisms to M.K. and H.K.), by the Strategic Research Program for Brain Sciences ("Development of Biomarker Candidates for Social Behavior," to M.K.; and "Bioinformatics for Brain Sciences," to H.K.) from the Ministry of Education, Culture, Sports, Science, and Technology (MEXT), Japan; by Mitsubishi Foundation, Takeda Foundation, and Toyoaki Foundation grants to M.M.; by the Uehara Memorial Foundation and Brain Science Foundation to Y.I.; and by a Research Grant from Human Frontier Science Program and CREST of JST to H.K. We thank M. Himeno, J. Saito, T. Sugiyama, C. Miura, M. Ogasawara, and K. Tamura for technical assistance; Drs. S. Chiken, Y. Masamizu, J. Noguchi, K. Sohya, and Y.H. Tanaka, and T. Nagaoka for technical advice; K. Ohara for help with the development of the task device; Drs. Y.R. Tanaka and S. Ishii for comments on the analysis software; and Drs. M. Kimura and G.J. Augustine for comments on the manuscript.

The authors declare no competing financial interests.

Correspondence should be addressed to Masanori Matsuzaki, Division of Brain Circuits, National Institute for Basic Biology, Myodaiji, 0kazaki, 444-8585, Japan. E-mail: mzakim@nibb.ac.jp.

DOI:10.1523/JNEUROSCI.2550-12.2013

Copyright $\odot 2013$ the authors $\quad 0270-6474 / 13 / 331377-14 \$ 15.00 / 0$
}

ences for the direction of a hand reach movement and the kinematic parameters of drawing tend to be similar in pairs of nearby units (Amirikian and Georgopoulos, 2003; Ben-Shaul et al., 2003; Georgopoulos et al., 2007; Stark et al., 2009). Neighboring motor cortex cells with the same direction preference, or the same response to change in wrist torques, tend to show strong synaptic linkages as represented by cross-correlations (Lee et al., 1998, Stark et al., 2008; Smith and Fetz, 2009). However, electrical recordings cannot resolve either the size or the number of cells in a functional cluster at a single-cell resolution. Recently, in vivo twophoton calcium imaging has revealed fine-scale distributions of running-, grooming-, licking-, and whisking-related cells in the motor cortex of awake mice (Dombeck et al., 2009; Komiyama et al., 2010; Huber et al., 2012). The distributions of these neurons are generally intermingled, but running- and grooming-related cells are sometimes partially segregated within an $\sim 100-\mu \mathrm{m}-$ scale micro-organization. However, the fine-scale distribution of task-related cells during forelimb movements such as reaching, drawing, and lever pulling has not been examined by two-photon imaging. In addition, how the fine-scale distribution of the activity of task-related cells temporally changes during movements is unknown. If there are fine-scale functional clusters, then what are their roles? If functional clusters are critically related to the execution of movements, then ensembles of clustered cells may carry more accurate information about the movements than nonclustered cells. Previous studies demonstrate that the ensemble activity of a small number of motor cortex neurons carries infor- 
A
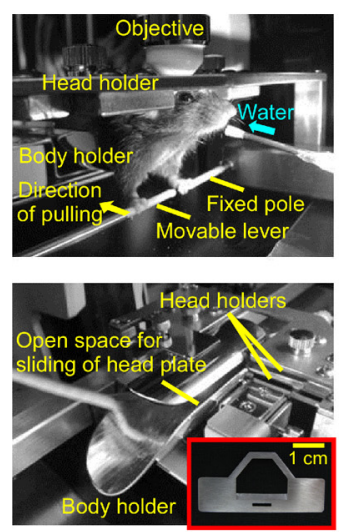

B

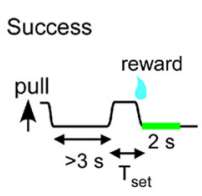

Error

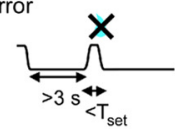

Error

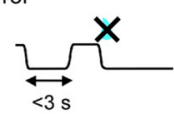

$\mathrm{C}$

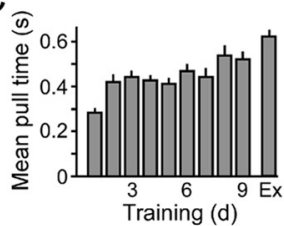

$\mathrm{E}_{\widehat{0}}$

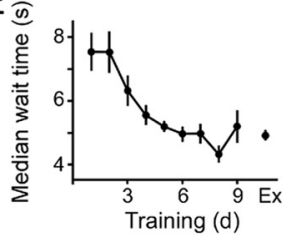

G

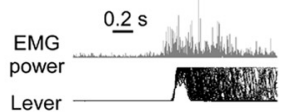

D

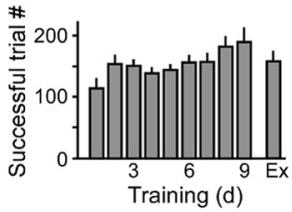

$\mathrm{F}$

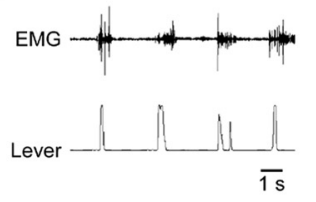

$\mathrm{H}$

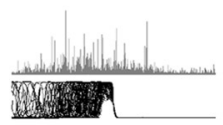

Figure 1. The lever-pull task in head-restrained mice. $A$, A mouse is shown in the task device. Top, The head of the mouse was fixed under an objective, and the right forelimb was available to grasp and pull the movable lever. The left forelimb grasped a fixed pole to keep the posture relaxed. A waterspout for reward delivery was near the mouth. Bottom, The mouse with the head plate was smoothly inserted into the body holder. The head plate (inset) slid through an open space in the body holder wall and was fixed between the head holders. $\boldsymbol{B}$, Schematic diagram of the lever-pull task. Before pulling the lever, mice had to wait for $>3 \mathrm{~s}$. After the lever pull was maintained for $T_{\text {sett }}$ a drop of water was dispensed and the lever was then rapidly pushed to the wait position by a solenoid pole. The lever was immobilized for $2 \mathrm{~s}$ in the wait position (green bar). When an animal did not maintain the lever pull for $T_{\text {set }}$ or did not wait at least $3 \mathrm{~s}$ before the level pull, a reward was not given and the mechanical lever push did not engage. C, The mean pull time increased over the $9 \mathrm{~d}$ training session ( $n=35$ mice) until the imaging experiment (Ex) was performed ( $n=21$ mice). $\boldsymbol{D}$, The number of successful trials during the $9 \mathrm{~d}$ training session and imaging experiment. $\boldsymbol{E}$, The median waiting time before successful trials decreased during the training sessions and $5.3 \pm 0.3 \mathrm{~s}$ ( $n=21$ mice) during the imaging session. $\boldsymbol{F}$, Representative traces of EMG activity of the right forelimb muscle (top) and lever trajectory (bottom) during task performance. $\boldsymbol{G}, \boldsymbol{H}$, EMG power coincided with the start $(\boldsymbol{G})$ and end $(\boldsymbol{H})$ of the pull movement.

mation about hand trajectories (Humphrey et al., 1970; Ashe and Georgopoulos, 1994; Wessberg et al., 2000; Paninski et al., 2004). However, whether the spatial distribution of these cells affects the amount of motor information remains unknown.

To address these issues, we developed a self-initiated lever-pull task and monitored the mouse cortex in vivo using two-photon calcium imaging. In layer $2 / 3$ of two forelimb motor areas (Neafsey et al., 1986), the rostral forelimb area (RFA) and caudal forelimb area (CFA), we prominently detected a functional cluster during the lever-pull movement. The ensemble activity of more than four cells that were clustered within a circular area with a diameter of $\sim 70 \mu \mathrm{m}$ more accurately predicted the lever movement trajectory than the same number of cells outside the cluster.

\section{Materials and Methods}

Animals. All experiments were approved by the animal experimental committee of the School of Medicine, University of Tokyo, and also by the Okazaki animal committee. C57BL/6 (wild-type) and C57BL/6 (Thy1-ChR2-YEFP; Wang et al., 2007) mice of either sex with ages of 2-6 months were used. Mice were anesthetized by intraperitoneal injection of ketamine/xylazine $(74 / 10 \mathrm{mg} / \mathrm{kg})$, and then an incision was made to the skin covering the neocortex. After the exposed skull was cleaned, a head plate was attached to the skull using dental cement (Fujiryu-to; GC). The surface of the intact skull was subsequently coated with clear acrylic dental resin (Super bond; Sun Medical) to prevent drying. Mice were allowed to recover for several days before experiments were performed.

Self-initiated lever-pull task. The voluntary forelimb movement task was modified from one used in rats (Isomura et al., 2009). Mice with head plates (Tsukasa Giken) were water-deprived in their home cages beginning the day before the start of the task and were allowed ad libitum access to $1 \mathrm{ml}$ of water until they were satiated after each training session. Mice were maintained at no less than $85 \%$ of their normal weight throughout the experiments. For the task, the mice were smoothly inserted into body chambers and their heads were fixed by placing the head plate between head holders that were attached to a stage (Fig. 1A). Each animal was trained to perform the voluntary (self-initiated) forelimb-movement task while being head-restrained in the task device for $1 \mathrm{~h}$ per day $(8-9$ training days). On the first day, head-restrained mice were rewarded whenever they pulled the lever $5 \mathrm{~mm}$, regardless of the lever-pull time. The reward was a $4 \mu \mathrm{l}$ drop of water from a spout near their mouths that was connected to a syringe pump. From the second training session onward, the lever-pull time $\left(T_{\text {set }}\right)$ required for reward acquisition was programmed to progressively increase $(100-1000 \mathrm{~ms})$ as performance improved. Within each session, $50 \mathrm{~ms}$ was added to $T_{\text {set }}$ for each successful trial unless $T_{\text {set }}$ exceeded a time that was manually determined before each session (500-1300 ms). Furthermore, $2.5 \mathrm{~ms}$ was subtracted from $T_{\text {set }}$ per second because monotonic increases in $T_{\text {set }}$ might have prevented successful trials. If the lever was not pulled, a weak magnetic force returned it to the wait position; thus, mice had to maintain pulling the lever for $T_{\text {set }}$. In these sessions, when the mice pulled the lever by $5 \mathrm{~mm}$ for $T_{\text {set, }}$, they were rewarded, and the lever was quickly brought back to the wait position by the force of a solenoid valve. The lever then could not be moved from the wait position for $2 \mathrm{~s}$. This solenoid force was not given to the mice after error trials. Mice were required to leave the lever in the wait position for $>3 \mathrm{~s}$ between the end of one lever pull and the initiation of the next lever pull. If a mouse did not wait for $3 \mathrm{~s}$, then the next trial was an error (Fig. 1B). Due to the mechanical force of the lever push and the immovability after each successful pull, there were unconstrained behaviors (pushing, holding, and releasing the lever) that took place during the task. The timing and duration of licking events were also unrestricted. Performances of the mice were monitored with an infrared video camera. A program that was written with LabVIEW (National Instruments) was used to regulate the timing of the reward, the lever return, and the immovability of the lever.

The lever position was continuously monitored as the displacement of a 1-mm-diameter magnetic bead (NeoMag; Seiko Sangyo), which was attached to the tip of the lever opposite the site exposed to the mice. A magnetoresistive sensor (HA-12; Macome) was used to detect the displacement of the magnetic bead.

EMG measurements. EMG signals were measured in one animal. After this mouse finished its final training session, it was anesthetized, and then two Teflon-insulated stainless steel wires were inserted through the forearm skin into the triceps brachii muscles and connected to an amplifier 
(Ex1, Dagan). After recovery for $2 \mathrm{~d}$, the mouse performed the lever-pull task. EMG activity was amplified, filtered $(0.1-2 \mathrm{kHz})$, and recorded.

Optogenetic stimulation mapping. Optogenetic stimulation mapping (OSM) was performed as described previously (Ayling et al., 2009; Hira et al., 2009). Briefly, channelrhodopsin-2 (ChR2) transgenic mice with head plates were anesthetized with ketamine/diazepam $(74 / 20 \mathrm{mg} / \mathrm{kg}$, i.p.). Supplemental doses were delivered intramuscularly whenever spontaneous limb movement appeared during the experiment. Photostimulation with a blue laser at $473 \mathrm{~nm}$ was performed in a lightly anesthetized state using an upright microscope (BX61WI; Olympus) and a FV1000-MPE laser-scanning microscope system (Olympus). Laser power and pulse duration were adjusted to a level that induced stable and visible responses in each experiment $(1-3 \mathrm{~mW}$ and 2-10 $\mathrm{ms}$, respectively). Either all or part of the field of view $[6.4 \times 6.4 \mathrm{~mm}$ when using $2 \times$ objective, numerical aperture (NA) of 0.08 , PlanApo, Olympus; or $2.6 \times$ $2.6 \mathrm{~mm}$ when using $5 \times$ objective, NA of 0.10 , MPlan, Olympus) of the cortical surface was divided into two-dimensional pixel arrays, and each pixel was then illuminated individually. The focal plane was adjusted to the surface vasculature. Assuming a Gaussian laser beam, the diameter of the beam at the focal plane was $\sim 3.8 \mu \mathrm{m}(2 \times 473 \mathrm{~nm} /[\pi \times 0.08])$. Assuming that the refractive index of brain tissue equals that of water (1.33), and that the laser beam entered the brain with a half-angle of $\arcsin =0.08 / 1.33$, then the diameter of the laser spot would be $72 \mu \mathrm{m}$ $(2 \times 600 \mu \mathrm{m} \times \tan [\arcsin [0.08 / 1.33]])$ at a depth of $600 \mu \mathrm{m}$ from the vasculature. A magnetic bead was attached to the back of the hand using cyanoacrylate glue. Limb movements were then measured using a magnetoresistive sensor to detect bead displacement. Movement data were low-pass filtered at $500 \mathrm{~Hz}$, sampled at $5-10 \mathrm{kHz}$, and recorded using FV1000-MPE software.

Intracortical microstimulation. Intracortical microstimulation (ICMS) was performed as described previously (Hira et al., 2009). Briefly, the mice were anesthetized as was done for OSM. The skull covering either the left or right cortical hemisphere was removed. Microelectrodes were inserted into the cortex at a depth of $>0.6 \mathrm{~mm}$. The stimulation parameters consisted of $45 \mathrm{~ms}$ trains with $0.4 \mathrm{~ms}$ cathodal pulses of $30-200 \mu \mathrm{A}$ at $333 \mathrm{~Hz}$. Contralateral forelimb movements were measured as described above.

Flavoprotein imaging. Head-restrained mice were deeply anesthetized with urethane $(1.6 \mathrm{~g} / \mathrm{kg}$, i.p.). Throughout the recordings, rectal temperature was maintained at $37^{\circ} \mathrm{C}$ with a silicon rubber heater $(5 \times 10 \mathrm{~cm})$ and a temperature controller (TR-P; AS One). Fluorescence imaging was performed according to the method of Tohmi et al. (2009), with a MiCAM02-HR system (BrainVision) and a $2 \times$ objective (NA of 0.14 , XLFluor, Olympus) mounted on an upright microscope (BX61WI, Olympus). Illumination was provided by $473 \mathrm{~nm}$ blue LEDs (LEX2-B; BrainVision). A wide green filter cube $(480-550 \mathrm{~nm}$ excitation filter, MSWG2; Olympus) was used to generate green light for excitation. Cortical images $(128 \times 168$ pixels after binning $)$ of endogenous green fluorescence $(500-550 \mathrm{~nm})$ in blue light $(470-490 \mathrm{~nm})$ were recorded with a cooled CCD camera system at 20 frames/s before, during, and after $1 \mathrm{~s}$ vibrations of the palm of the right forelimb at $217 \mathrm{~Hz}$ that were generated with a flat coreless vibration motor (FM34F; TPC). This stimulation moved the whole right forelimb, including the proximal and distal arm and digits, so it was assumed to induce both proprioceptive and cutaneous sensations. Trials were repeated at least 10 times at $5 \mathrm{~s}$ intervals. The averaged images were spatially filtered. Somatosensory forelimb area (SFA) was defined as the area with a relative fluorescence change that was greater than half of the peak value in the imaged field $1 \mathrm{~s}$ after the initiation of vibration.

Muscimol injection. Nine mice were used for the muscimol injection experiment after they completed the training sessions. A glass pipette with a solution containing muscimol hydrobromide $(5 \mu \mathrm{g} / \mu \mathrm{l}$; SigmaAldrich) was inserted through a cranial window into the left RFA, CFA, or barrel cortex at a depth of $\sim 250 \mu \mathrm{m}$ from the cortical surface while the mice were head-restrained in the task device. The pipette tip diameter was $\sim 30 \mu \mathrm{m}$. After mice performed $40-50$ successful trials of the lever pull, the solution was then injected at 1.5 psi for $1 \mathrm{~min}$. After each injection, the pipette was removed from the cortex and pressure was reapplied to confirm that the pipette tip was not clogged. The number of successful trials was counted and compared before and after the injections. The injected volume was estimated to be $\sim 60 \mu \mathrm{l}$ by determining the reductions in the volume of solution in the pipette after repeated injections. This amount was similar to that used in other studies (70 $\mu$ l used by Komiyama et al., 2010; $50 \mu$ l used by Harvey et al., 2012). Licking ability was not inhibited because mice given muscimol could lick a water drop that was manually administered to their mouths. Muscimol injection into both hemispheres may be necessary for complete inhibition (Komiyama et al., 2010).

Calcium dye loading and two-photon imaging. On the day they were imaged, mice were subjected to a second surgery under isoflurane anesthesia. An 2-mm-diameter circular craniotomy was made over the RFA (circle centered at $\sim 1 \mathrm{~mm}$ lateral and $\sim 2.5 \mathrm{~mm}$ rostral to bregma) or the CFA (circle centered at $\sim 1.2 \mathrm{~mm}$ lateral and $\sim 0.5 \mathrm{~mm}$ rostral to bregma), and the dura mater was removed. A total of $10 \mathrm{~mm}$ Oregon Green 488 BAPTA-1 AM (OGB-1 AM; Invitrogen) was dissolved in dimethyl sulfoxide mixed with 20\% (v/v) Pluronic F-127 (Invitrogen) and then diluted tenfold in a solution containing (in mM) $125 \mathrm{NaCl}, 5 \mathrm{KCl}, 1$ $\mathrm{MgCl}_{2}, 5 \mathrm{HEPES}$, and 0.05 Alexa Fluor 594, $\mathrm{pH}$ 7.4. A glass pipette with a $12-15 \mu \mathrm{m}$ tip diameter was filled with the diluted solution and inserted into layer $2 / 3$ of the cortex. OGB- $1 \mathrm{AM}$ was then injected at $0.5-2$ psi over $\sim 3 \mathrm{~min}$. The area stained by the dye was visualized using a two-photon laser-scanning system (FV1000-MPE) coupled with a mode-locked Ti: sapphire laser (MaiTai HP; Spectra Physics) at a wavelength of $830 \mathrm{~nm}$. After the injection, 4\% (w/v) high-concentration agarose L (Nippon Gene) was placed over the craniotomy, a $4.5-\mathrm{mm}$-diameter glass coverslip (Matsunami Glass) was pressed onto the agarose surface, and the edges were sealed with dental cement. This treatment was crucial for preventing axial $(Z)$-motion of the imaging plane during task performance. Mice were then returned to their cages.

After waking from the isoflurane anesthesia, mice were headrestrained under the microscope. During performance of the lever-pull task, two-photon images were acquired with a FV1000-MPE system with either a $40 \times$ (LUMPlanFl, NA of 0.8 ; Olympus) or a $25 \times$ objective (XLPlan, NA of 1.05; Olympus). The laser intensity used was $2-40 \mathrm{~mW}$. The imaged fields were $209.0 \pm 29.9 \mu \mathrm{m}($ mean \pm SD $) \times 102.5 \pm 7.8 \mu \mathrm{m}$ at depths below the cortical surface of $204.3 \pm 8.9 \mu \mathrm{m}$ (mean \pm SD) in the RFA ( $n=40$ fields of 11 mice), and $209.8 \pm 35.6 \mu$ m (mean \pm SD $) \times$ $107.7 \pm 11.8 \mu \mathrm{m}$ at depths of $218.5 \pm 9.4 \mu \mathrm{m}$ in the CFA $(n=28$ fields of 10 mice). The pixel size was $0.62 \pm 0.0 \mu \mathrm{m}$ (mean \pm SD) in the RFA and $0.69 \pm 0.1 \mu \mathrm{m}$ in the CFA. Continuous 1000-frame imaging was repeated in each field for $10-30 \mathrm{~min}$. The frame duration was $311 \pm 27$ $\mathrm{ms}$ (mean $\pm \mathrm{SD}, 250-349 \mathrm{~ms}$ ) in the RFA and 316 $\pm 21 \mathrm{~ms}$ (263-354 ms) in the CFA. The image data, lever positional signal, and solenoid signal were all simultaneously recorded by the FV1000-MPE system.

Cell-attached recording. Head-restrained mice were subjected to surgery and experiments under deep urethane anesthesia $(1.6 \mathrm{~g} / \mathrm{kg}$, i.p.) with their rectal temperature maintained at $37^{\circ} \mathrm{C}$. One to $3 \mathrm{~h}$ after OGB- $1 \mathrm{AM}$ injection, glass microelectrodes (open-tip resistance, 2-3 $\mathrm{M} \Omega$ ) with an extracellular solution consisting of (in $\mathrm{mm}$ ) $140 \mathrm{NaCl}, 4 \mathrm{KCl}, 2 \mathrm{CaCl}_{2}, 1$ $\mathrm{MgCl}_{2}, 5 \mathrm{HEPES}$, and 0.05 Alexa Fluor 594, $\mathrm{pH}$ of 7.4, were attached to OGB-1-loaded cells that were detected by simultaneous two-photon imaging. The electrical signal in a loose-patch configuration was detected with an amplifier (AxoPatch B700; Molecular Devices), bandpass filtered at $0.5-1.5 \mathrm{kHz}$, sampled at $10 \mathrm{kHz}$, and recorded by a program written with LabVIEW. The field including the attached cell was simultaneously imaged at a frame duration of $306 \pm 13 \mathrm{~ms}$ (mean $\pm \mathrm{SD}, n=6$ fields from two mice).

Processing of imaging data and definition of task-related cells. Analyses were performed using an ImageJ plug-in $(1.37 \mathrm{v} ; \mathrm{NIH})$ and scripts that were written in MATLAB (version 7; MathWorks). Movies were corrected for focal plane displacements $(X, Y$, and rotation-angle shifts) using TurboReg (Thévenaz et al., 1998). However, this procedure was not always sufficient to compensate for within-frame distortions, so a line-by-line registration method that was modified from a Hidden Markov Model (HMM) algorithm (Dombeck et al., 2007) was also applied to correct $X$ and $Y$ shifts. The SDs of $X$ and $Y$ shifts between the raw image frames and the motion-corrected image frames during the imaging sessions were $1.34 \pm 0.70 \mu \mathrm{m}$ (mean $\pm \mathrm{SD}, n=68$ imaged fields), 
Table 1. The number and percentage of task-related cells

\begin{tabular}{llcrrrr}
\hline & Reconstructed (100\%) & Task-related (\%) & Pull (\%) & Post-pull (\%) & Other task-related (\%) & Non-task-related (\%) \\
\hline RFA (40 fields) & $1333(100)$ & $966(72.5)$ & $685(51.4)$ & $269(20.2)$ & $12(0.9)$ & $367(27.5)$ \\
CFA (28 fields) & $1028(100)$ & $677(65.9)$ & $469(45.6)$ & $206(20.0)$ & $2(0.2)$ & $351(34.1)$ \\
All (68 fields) & $2361(100)$ & $1643(69.6)$ & $1154(48.9)$ & $475(20.1)$ & $14(0.6)$ & $718(30.4)$ \\
\hline
\end{tabular}

The percentages were calculated from all data pooled across RFA, CFA, and both imaged fields. Parentheses indicate the percentage over total data across corresponding imaged fields.

and $0.95 \pm 0.41 \mu \mathrm{m}$, respectively. The SDs of $X$ and $Y$ shifts during periods that started $2 \mathrm{~s}$ after the end of lever pulls and finished $2 \mathrm{~s}$ before the start of the next lever pulls ("wait periods") during the imaging sessions were $0.70 \pm 0.35 \mu \mathrm{m}$ and $0.50 \pm 0.17 \mu \mathrm{m}$, respectively. Furthermore, the SDs of the periods that started $1.5 \mathrm{~s}$ before and ended $2 \mathrm{~s}$ after the start of each successful lever-pull trial ("task-related periods") were $1.50 \pm 0.87 \mu \mathrm{m}$ and $1.0 \pm 0.39 \mu \mathrm{m}$, respectively. The SDs of the rotationangle shifts were $0.11 \pm 0.04^{\circ}$ during wait periods and $0.20 \pm 0.08^{\circ}$ during task-related periods. Thus, although motion displacements were larger in task-related periods than wait periods, the SDs were comparable to the displacements of $\sim 2 \mu \mathrm{m}$ that were observed while mice ran on tracking balls as described by Dombeck et al. (2007). Although $Z$ motions are generally less than lateral motions during the awake state (Dombeck et al., 2007; Greenberg and Kerr, 2009), slow $Z$ drifts during the imaging session were corrected by examining every 1000 frames of the imaged field for $Z$ shifts by visual inspection. If any shifts were detected, then the imaging planes were manually corrected to fit the reference imaged frames that were acquired before the imaging sessions. The next 1000 frames were then acquired in the same field. The maximum $Z$-motion correction in this study was $\sim 2 \mu \mathrm{m}$.

The outlines of the cell-based region of interest (ROI) were determined using a semiautomated algorithm based on maximization of correlation coefficients among intensities of nearby pixels over time, along with cell sizes and shapes, and were confirmed by visual inspection. Backgrounds from unstained blood vessels were subtracted from the averaged signals across all pixels included in each ROI. To remove slow time scale changes in the fluorescence time series (Dombeck et al., 2007), the eighth percentile value of each $30 \mathrm{~s}$ segment into which all movies were split was assigned as the center time point of each segment. The corresponding values at the flanking center time points were then smoothly interpolated at every time point between them, and the interpolated value was subtracted at every time point.

The skewness of the distribution, which corresponds to the central third-order moment normalized to the cube of the SD, was used to characterize statistical sparseness and search for statistical signatures of individual cells (Mukamel et al., 2009). ROIs that demonstrated skewness of $>0.3$ were selected. Following this selection, eight ROIs with clear negative transients and 16 ROIs with gradually (a few seconds) increasing and decreasing transients were excluded from all 68 imaged fields after visual inspection. The remaining cells ( 1333 cells in RFA and 1028 cells in CFA) were defined as reconstructed cells. When the values of calcium transients in individual imaged frames, which were deconvoluted with a decay time constant of $1 \mathrm{~s}$, exceeded a threshold (their median plus their median absolute deviation $\times 1.426 \times 3$ ), the values were defined as inferred events. Otherwise the inferred events were zero. When spikes between two flanking imaging time points were measured with cellattached recordings and the inferred event at the latter imaging time point was not zero, then the spikes were considered as detected. When the relative fluorescence changes $(\Delta F / F)$ were analyzed, signals between imaging frames were linearly interpolated every $50 \mathrm{~ms}$ from $\Delta F / F$ of the two flanking images. The scan timings related to the $Y$ position of the cells were taken into account in this interpolation procedure and the lever positions and reward timings were downsampled to $50 \mathrm{~ms}$ time bins.

Among these reconstructed cells, an individual cell was defined as task-related when $\Delta F / F$ during all task-related periods was significantly larger ( $p<0.05$ in Wilcoxon rank sum test) than $\Delta F / F$ during all wait periods. Of the reconstructed cells, 966 and 677 were classified as taskrelated in the RFA and CFA, respectively (Table 1). For each task-related cell, $\Delta F / F$ was then aligned to either the start or end time of all successful lever movements at time 0 , and then averaged over all successful trials and defined as $F_{\text {start }}$ and $F_{\text {end }}$, respectively. Cells with $F_{\text {start }}$ at peak times of $>0$ s were collected. To estimate the peak amplitude of $F_{\text {end }}$ at time $>0$ $s$ without the decay component of $F_{\text {end }}$ at time $\leq 0$ s (during the lever-pull period), $F_{\text {end }}$ at time $>0$ s was subtracted by the value of $F_{\text {end }}$ at time 0 multiplied by the exponential decay at each time point $\left(F_{\text {end }}(t)-F_{\text {end }}\right.$ $\left.(0) e^{-t / 1}\right)$. Cells were classified as pull cells when the maximum $F_{\text {end }}$ value at time $\leq 0 \mathrm{~s}\left(\max _{t \leq 0} F_{\text {end }}(t)\right.$ was larger than $\max _{t>0} F_{\text {end }}(t)-F_{\text {end }}$ $\left.(0) e^{-t / 1}\right)$ ) (see Fig. 5). The remaining cells were considered post-pull cells. Task-related cells that did not belong to these two types were defined as other task-related cells ( 12 cells in RFA and two cells in CFA). Lever return-related cells were defined as cells whose activity after the end of the lever pull in the error trials was significantly larger than that before the end of the lever pull ( $p<0.05$; Wilcoxon signed-rank test). Finally, licking-related cells were defined as cells whose activity in the wait period during licking (and without forelimb or body movements) was significantly larger than the wait period without licking $(p<0.05$; Wilcoxon rank sum test).

Estimation of functional clusters. To quantify the time course of the functional clustering, geometric energy $E_{g}$ in each imaged field was introduced,

$$
E_{g}=-\sum_{j>i} J_{i j} F_{i} F_{j}, \quad J_{i j}=\frac{\frac{1}{r_{i j}}}{\sum_{n>m} \frac{1}{r_{m n}}},
$$

where $F_{i}$ and $F_{j}$ are the normalized values $(0-1)$ of $\Delta F / F$ of task-related cells $i$ and $j$, respectively, and $r_{i j}$ is the distance between cells $i$ and $j$. The denominator of $J_{i j}$ was used to normalize the distribution of the cellular distances across imaged fields. By restricting the range of $F_{i}$ from 0 to $1, E_{g}$ ranged from -1 to $0 . \Delta E_{g}$ was defined as $E_{g}-\hat{E}_{g}$, where $\hat{E}_{g}=-\left\langle F_{i} F_{j}\right\rangle$, and $\checkmark$ denoted the mean across cell pairs. Thus, $\Delta E_{g}$ ranged from -1 to $1 . \Delta E_{g}$ was calculated over the imaging sessions in each imaged field. To determine whether $\Delta E_{g}$ was statistically negative during a task-related period, it was compared with shuffling data. First, $\Delta E_{g}$ was aligned to the start of each successful trial and averaged over all successful trials. Then, to simulate shuffling, the location of each cell was randomly reassigned to one of the reconstructed cells in the same imaged field. Next, $\Delta E_{g}$ was again calculated over the imaging sessions and averaged over all successful trials. This procedure was repeated 1000 times, and $1000 \Delta E_{g}$ values were obtained from the shuffling data. Finally, the value of the actual $\Delta E_{g}$ was ranked relative to the 1000 values from the shuffling data at each time point. When the actual $\Delta E_{g}$ was below the lowest 50th value of the shuffling data, it was considered significantly negative. When spike $\Delta E_{g}$ values were calculated, $F_{i}$ was the normalized value $(0-1)$ of the filtered inferred event of task-related cell $i$, and the value of the inferred event in each imaging frame was Gaussian-filtered (SD of $200 \mathrm{~ms}$ ) to interpolate the values between flanking imaging frames with a time bin of $50 \mathrm{~ms}$.

The maximum number of pull cells, without other reconstructed cells, within a circular area in every imaged field was determined in a series of steps. First, the center of a circle was determined in the imaged field. Then, its diameter was elongated so that all cells included within the circle were pull cells. Then, the center position was systematically changed and the maximum number of pull cells in each circle was estimated. Circles with more than four pull cells were defined as clusters. The cluster with the maximum number of pull cells in each imaged field was defined as a primary cluster. Pull cells within the primary cluster were defined as primary-clustered cells. Pull cells that were not included in any clusters were defined as nonclustered cells. Pull cells that were neither primary-clustered cells nor nonclustered cells were defined as other clustered cells. 
A

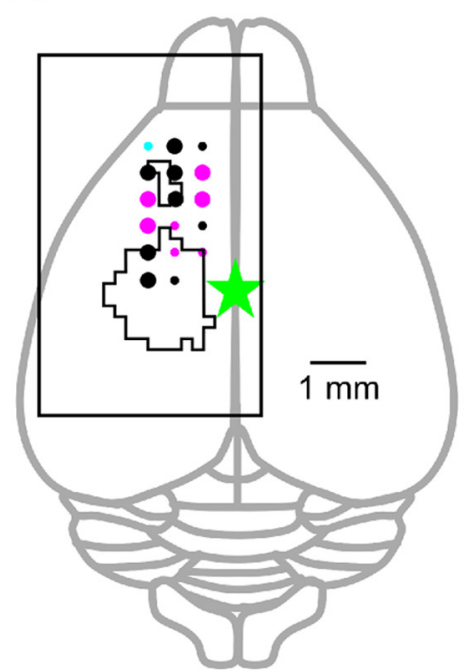

B

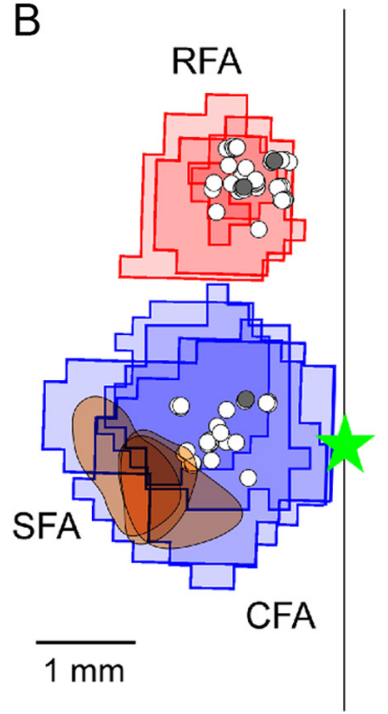

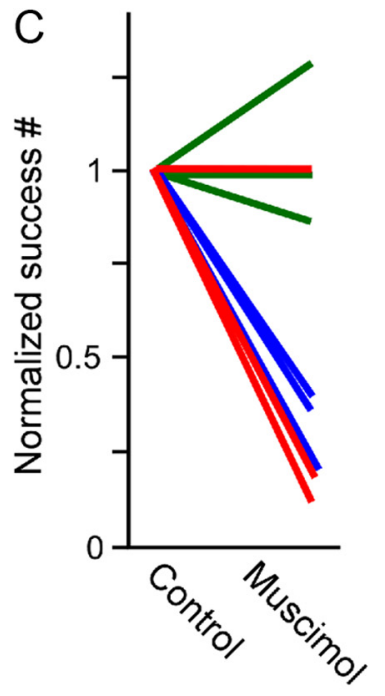

Figure 2. RFA and CFA as identified by OSM and ICMS. A, OSM and ICMS results in an animal. OSM was performed in the boxed region. The contour lines at $10 \%$ of the maximal amplitude of contralateral forelimb movement as determined by OSM are shown. The dots indicate the sites where ICMS induced contralateral forelimb movement (black), whisker movement (magenta), or no movement (cyan). The current amplitudes were $<200 \mu \mathrm{A}$ and $>200 \mu \mathrm{A}$ at the large and small dots, respectively. The green star indicates the bregma. B, RFA, CFA, SFA, and the imaged fields. Overlaid red and blue contours show the RFA and CFA, respectively, as revealed by OSM ( $n=4$ mice). Two maps acquired in the right hemisphere are mirror-reversed. Orange contours show SFA as determined by flavoprotein imaging ( $n=3$ mice). The contour lines at $50 \%$ of the maximal response to $1 \mathrm{~s}$ vibration of the contralateral forelimb are overlaid. Circles indicate the centers of the two-photon calcium imaged fields during the task. Three closed circles show the centers of the imaged fields that were confirmed to be the RFA or CFA by OSM after the imaging experiment. C, Effects of muscimol injection into the left hemisphere of the RFA (red), CFA (blue), or somatosensory barrel cortex (green) on lever-pull task performance. Muscimol was injected into each indicated area in three animals. The number of successful lever pulls in the $5 \mathrm{~min}$ after the injection was normalized to the number of successful pulls in the 5 min before the injection.
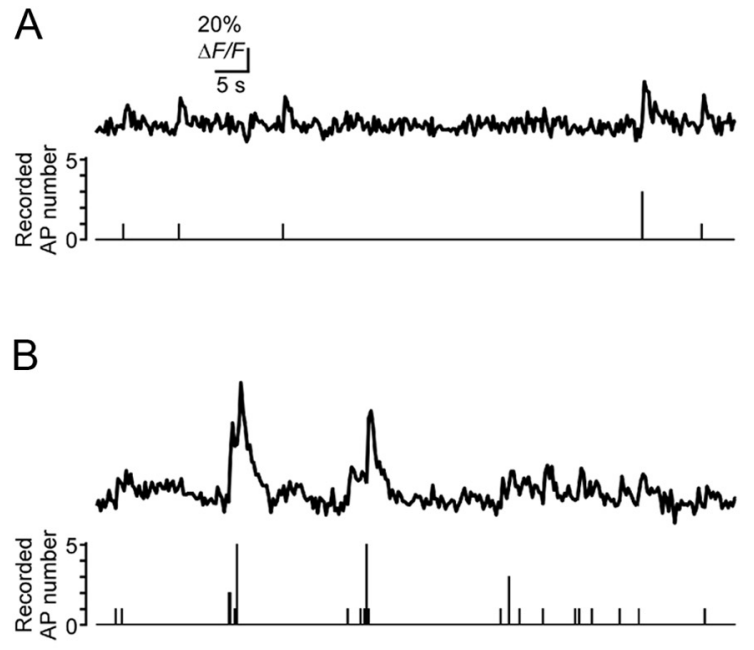
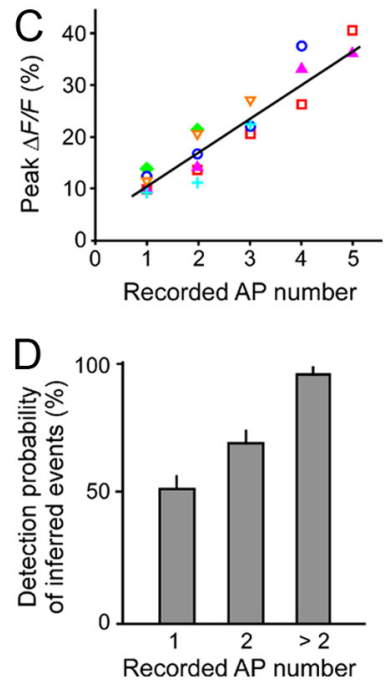

Figure 3. Relationship between calcium transients and firings. $A, B$, Example traces of simultaneous two-photon imaging and cell-attached recordings from two different cells. Top traces show the fluorescent traces of the attached cell somas. Bottom traces show the number of recorded APs from an attached cell between two flanking imaging time points. C, Peak $\Delta F / F$ as a function of the number of recorded APs. The number of APs between two flanking imaging time points and the peak $\Delta F / F$ at the latterimaging time points were compared for every time point. Different colored symbols indicate the mean peak values for each number of APs from individual cells ( $n=6$ cells from two mice). A regression line for all points is shown. Spearman's rank correlation coefficient was 0.94 . D, Detection probability of inferred events for each recorded AP number.

Prediction of lever movement trajectory. The ensemble activity was fitted to a one-dimensional lever trajectory by applying a linear model (Wessberg et al., 2000). In this model, the lever trajectory $\mathbf{L}(t)$ is

$$
\mathbf{L}(t)=\mathbf{b}+\sum_{u=0}^{3} \mathbf{a}(u) \mathbf{X}(t-u)+\varepsilon(t),
$$

where $\mathbf{b}$ is the $\mathbf{L}$-intercept in the regression, $\mathbf{a}(u)$ is the set of weights required for the fitting as a function of imaged frame time lag $u, \mathbf{X}(t)$ is the matrix consisting of the inferred event of each cell at each imaged frame, and $\varepsilon(t)$ is the residual error. The inferred events, and not $\Delta F / F$, were used as the values for $\mathbf{X}(t)$ so that the effects of the decay component of $\Delta F / F$ did not contaminate the results. However, even when $\Delta F / F$ values were used for $\mathbf{X}(t)$, the conclusions were the same (data not shown). To estimate whether ensemble activity was relevant to the immediately subsequent and coincident movement, four frames imaged $\sim 1 \mathrm{~s}$ before each lever position were used for the fitting. Time bin was the duration of each imaged frame. The calculation was performed using the MATLAB statistics toolbox. The activities of ensembles and single cells of the primary-clustered and nonclustered cells were compared. Cross validation was used to estimate the prediction accuracy of the lever trajectory by dividing each imaging session into five segments (Hastie et al., 2009). Four segments were used as a training set to construct the linear model, and the lever trajectory was then predicted by this constructed model in the remaining segment. The prediction was performed for each segment, and the correlation coefficient $(c)$ between the overall predicted trajectory and the real trajectory was calculated. The relationship between $c$ and cell number in each imaged field was estimated by neuron-dropping analysis (Wessberg et al., 2000). The neuron-dropping analysis was performed by calculating $c$ from remaining neural ensemble activity when a single cell was randomly removed from an imaged field. This single cell removal and subsequent prediction was then repeated until only one cell remained in the imaged field. This procedure was repeated 100 times for each ensemble, and the values for every number of observed cells were averaged. The mean values determined for smaller numbers of primaryclustered cells and nonclustered cells were compared. 
Cross-correlations between task-related activities. Trial-to-trial cross-correlations (tCCs) between pairs of task-related cells were calculated as Pearson's correlation coefficients between two vectors comprising the mean $\Delta F / F$ of the pairs of cells during the task-related period of each successful trial. All tCC values were pooled across chosen fields and displayed as groups according to cell type and distance.

Statistics. Data are presented as the mean \pm SD unless otherwise stated. Error bars on graphs correspond to the SEM. The Wilcoxon signed-rank test, Wilcoxon rank sum test, Pearson's correlation, and Spearman's rank correlation test were used for statistical comparisons. For multiple comparisons shown below in Figure $8, A$ and $F, p$ values were multiplied by the number of simultaneously tested sets.

\section{Results}

Development of a self-initiated, headrestrained, lever-pull task for mice

To carry out two-photon calcium imaging while mice performed a self-initiated movement, we developed a head-restrained lever-pull task (Fig. 1A,B). Mice used their right forelimbs to pull the lever for a given amount of time $\left(T_{\text {set }}\right)$ and were subsequently rewarded with a drop of water from a spout near their mouth. Simultaneously with the reward at the cessation of the lever pull, a magnet-controlled solenoid pole quickly pushed the lever back to the wait position. The mice then had to wait $3 \mathrm{~s}$ before they could receive another reward for a lever pull. During the training sessions, the task difficulty was increased by gradually increasing the $T_{\text {set }}$ (100-1000 ms; see details in Materials and Methods), and mice were able to either increase or maintain the number of successful trials (Fig. 1C,D). Furthermore, the interval time between successful trials decreased (Fig. 1E), indicating that mice successfully learned how to pull the lever during $T_{\text {set }}$ and also understood that they had to wait $>3 \mathrm{~s}$ to pull the lever again and obtain another reward. After 8-9 training sessions, the mice executed this task under a microscope while two-photon imaging was simultaneously performed. During the imaging sessions, mice succeeded in $152 \pm 20$ trials $(n=21$ mice) with a $T_{\text {set }}$ of $622 \pm 41 \mathrm{~ms}$. The number of error trials after $>3 \mathrm{~s}$ of waiting was $136 \pm 93(n=21$ mice), and the number of error trials after $<3$ s of waiting was $56.0 \pm 29.8$. An EMG of the right forelimb after nine training sessions revealed that the onset of muscle activity occurred $\sim 100$ ms before the start of the lever pull, and muscle activity ceased $\sim 400 \mathrm{~ms}$ after the end of the lever pull (Fig. $1 F-H)$.

\section{Identification of RFA and CFA}

We used ChR2 mice to determine the forelimb motor areas over the broad neocortical surface by OSM using blue-laser scanning of the cortical surface (Ayling et al., 2009; Hira et al., 2009). Laser illumination induced forelimb movements in two distinct areas (Fig. 2A,B). These motor forelimb areas that we determined by
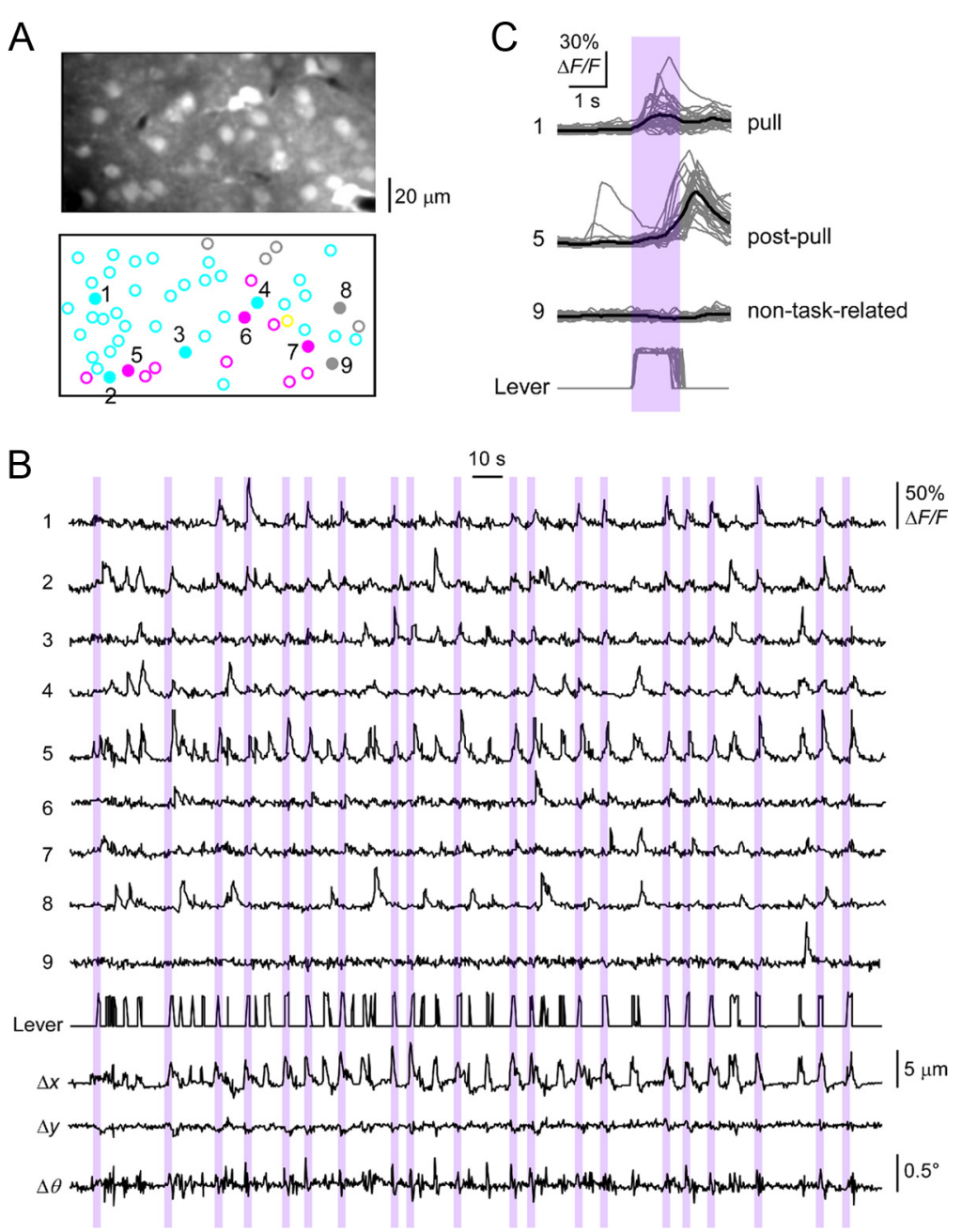

Figure 4. Activities of layer $2 / 3$ motor cortex cells during task performance. $\boldsymbol{A}, \mathrm{A}$ representative example of a two-photon 作, and non-task-related cells, respectively. $\boldsymbol{B}$, Traces $(270 \mathrm{~s})$ of motion-corrected calcium transients of the numpull cells, cells 5-7 were post-pull cells, and cells $8-9$ were non-task-related cells. $C$, The motion-corrected traces of cells 1,5 , and 9 are aligned with the start of all 30 successful lever pulls during the imaging session. Black thick lines indicate the mean traces. The lever trajectories in individual trials are overlaid in the bottom trace.

OSM corresponded to the areas that we determined by ICMS (Fig. 2A). These areas are known as RFA (the more rostral area) and CFA (the more caudal area), and have previously been identified by ICMS in the rat and mouse cortex (Neafsey et al., 1986; Tennant et al., 2011). The RFA location that we determined was similar, but slightly anterior, to the RFA location reported by Tennant et al. (2011). We found that RFA and CFA were necessary for lever pulling because muscimol injection into the left RFA or CFA inhibited lever pulling, whereas muscimol injection into the left barrel cortex did not $(n=3$ mice for each injection; Fig. 2C). Licking and left forelimb movements did not appear to be inhibited by any of these injections.

\section{Two-photon calcium imaging of motor cortex cells during task performance}

Simultaneous two-photon imaging and cell-attached recording in layer $2 / 3$ of the left CFA in anesthetized mice showed that both single and multiple action potentials (APs) induced robust relative fluorescence changes $(\Delta F / F)$ with peak amplitudes that cor- 
A
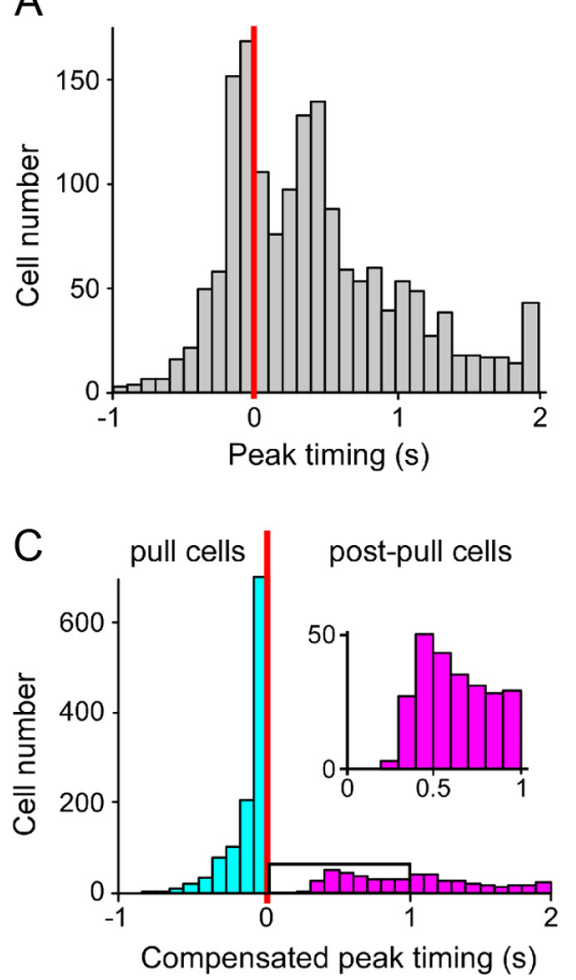

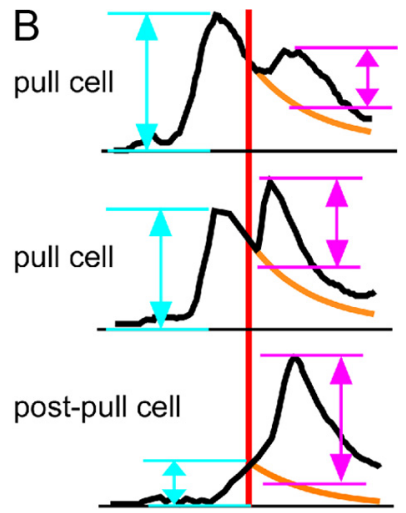

D

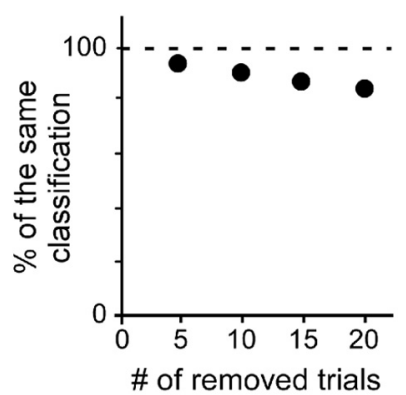

Figure 5. Classification of pull cells and post-pull cells. $A$, A histogram showing the timing of the mean peak $\Delta F / F$ values of 1643 task-related cells across all 68 imaged fields (21 mice). The end time of successful lever pulls was set as time $0 . \boldsymbol{B}$, Schematic examples of mean $\Delta F / F$ of two pull cells and one post-pull cell. The cyan peak amplitude before the end of the lever pull $\left(\max _{t \leq 0} F_{\text {end }}(t)\right)$ was compared with the peak amplitude after the end of the lever pull, subtracted by the orange exponential decay component of the amplitude at the end of the lever pull $\left(\max _{t>0}\left(F_{\text {end }}(t)-F_{\text {end }}(0) e^{-t / 1}\right)\right.$ (magenta). This comparison allowed the determination of whether the cells were pull or post-pull cells. The middle example was defined as a pull cell because the cyan amplitude was larger than the magenta one, even though the peak timing was after the end of the lever pull. $\boldsymbol{C}$, A histogram showing the timing of the mean peak activities of 1154 pull cells (cyan) and 475 post-pull cells (magenta) after the decay component of $\Delta F / F$ at the end of the lever pull was subtracted. The inset is an expansion of the boxed region from time 0 to 1 s. $D$, The percentage of cells that were classified as the same cell types is plotted against the number of removed successful trials. The same number of trials was randomly removed from each field, the activity of each task-related cell was averaged across the remaining trials, and then the cells were classified. For each number, the trials were randomly removed 20 times. The mean percentages across 20 classifications are shown as dots. All SEM bars were within the dots.

related to the number of APs (Fig. $3 A-C$ ). The mean peak amplitude and mean decay time of single AP-evoked calcium transients were $11.1 \pm 1.9 \%$ and $1.0 \pm 0.2 \mathrm{~s}(n=6$ cells from two mice), respectively. These values were consistent with previous results (Kerr et al., 2005; Hofer et al., 2011). After deconvolution of calcium transients, $94 \pm 8 \%$ of the firings with $\geq 3$ APs that occurred between two-flanking imaging time points (burst firings) could be detected as inferred events (Fig. 3D). The falsepositive rate was $10.6 \pm 3.7 \%(n=6$ cells $)$.

Next, we performed two-photon calcium imaging in layer $2 / 3$ of the left RFA ( 40 fields of 11 mice) or CFA ( 28 fields of 10 mice) while mice executed the task (Figs. $2 B, 4 A$ ). The numbers of successful and error trials were 55.1 \pm 23.9 and $68.5 \pm 28.0$ per imaged field in the RFA, respectively, and $48.6 \pm 22.3$ and $48.9 \pm$ 26.5 per imaged field in the CFA respectively. Most of the fields that we imaged did not overlap with the SFA that was previously determined with flavoprotein fluorescence imaging (Tohmi et al., 2009) (Fig. 2B). Three imaged fields were subsequently verified as the motor forelimb areas by OSM (Fig. 2B). To correct for motion displacement (lateral shifts and rotation-angle shifts) when we reconstructed spatially undistorted images and fluorescent traces, TurboReg, and a line-by-line algorithm based on the HMM (Dombeck et al., 2007) were applied (Fig. 4B,C). The maximum lever movement-related lateral displacement corrected by these procedures was $\sim 5 \mu \mathrm{m}$ along $x$-axis, which was comparable to the maximum lateral displacement of $\sim 3-5 \mu \mathrm{m}$ described by Dombeck et al. (2007) during running behaviors. The SDs of $X, Y$, and rotationangle shifts during periods starting $1.5 \mathrm{~s}$ before and ending $2 \mathrm{~s}$ after the start of each successful trial (task-related periods) were $1.50 \pm 0.87 \mu \mathrm{m}, 1.0 \pm 0.39 \mu \mathrm{m}$, and $0.20 \pm 0.08^{\circ}$ ( $n=68$ fields), respectively. The motion corrections were clearly effective for removal of motion artifacts. For example, the motion-corrected fluorescent trace of cell 9 in Figure $4 A$ was stable without any apparent distortion during the lever-pull movement (Fig. $4 B, C)$. Thus, we concluded that motioncorrected calcium transients in the awake state reflected spiking activity, and particularly the bursting firing of individual cells, even though the upper limit of signal detection of the firing was the value determined in the anesthetized state as described above.

\section{Classification and characteristics of pull cells and post-pull cells}

From the motion-corrected image sequences, we detected $33.3 \pm 14.0(12-74)$ and $36.7 \pm 13.0(8-67)$ reconstructed cells per imaged field in the RFA and CFA, respectively. We defined cells that exhibited significantly large calcium transients during the task-related periods as taskrelated cells ( 966 cells in RFA and 677 cells in CFA; see Materials and Methods; cells 1-7 in Fig. 4, and Table 1). There were two groups of task-related cells whose mean peak $\Delta F / F$ values occurred both before and after the end of the lever pulls (Figs. $4 C, 5 A$ ). To categorize these cells, we subtracted the decay components of $\Delta F / F$ at the end of the lever pulls from the $\Delta F / F$ values obtained after the end of the lever pull. We then further classified task-related cells into the cells with larger peak $\Delta F / F$ values during lever pulls ("pull cells") and the cells with the larger peak $\Delta F / F$ values after the end of lever pulls ("post-pull cells") (Figs. 4C, $5 B, C$; see details in Materials and Methods). The percentage of post-pull cells with compensated peaks from 0 to $0.3 \mathrm{~s}$ after the lever pull was very small (Fig. $5 C$ ). This was because $89 \%$ of cells that had a peak from 0 to $0.3 \mathrm{~s}$ in Figure $5 \mathrm{~A}$ displayed the activity at time 0 with $>60 \%$ of the peak amplitude. Therefore, these cells were actually classified as pull cells $(60 \%>100-$ $\left.60 \% \times e^{-0.3 \mathrm{~s} / 1 \mathrm{~s}}\right)$. Even when 5-20 successful trials in each field were randomly removed from the averaged activities, $>80 \%$ of all task-related cells were classified as the same cell types as when all successful trials were averaged (Fig. 5D). Thus, the timing of the peak activity of each cell was stable over multiple successful trials. Pull cells comprised approximately half of the reconstructed cells in both the RFA and CFA (51\% and 46\%, respectively, Table 1). As the characteristics of task-related cells were similar in RFA and CFA, data from RFA and CFA were pooled in the following analyses. A total of $44 \%$ of pull cells (509 of 1154 in 
A

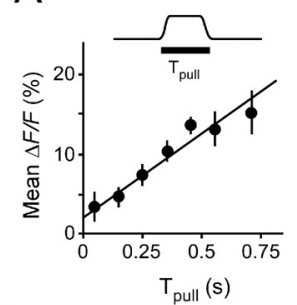

$\mathrm{E}$
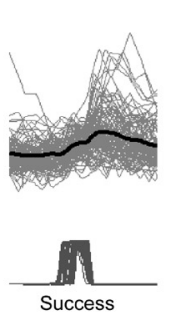

B

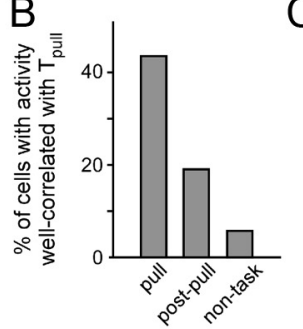

F
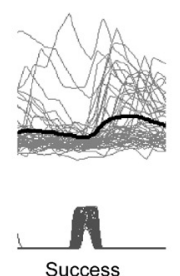

C
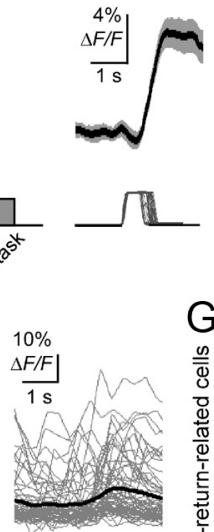

M.T.

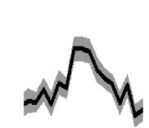

Vibration

G

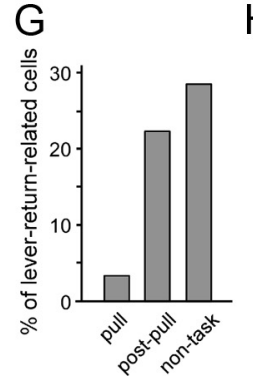

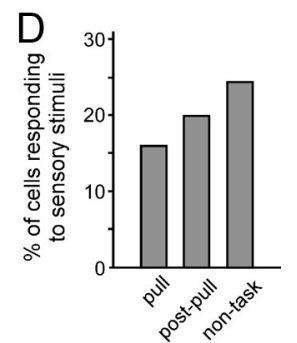

$\mathrm{H}$

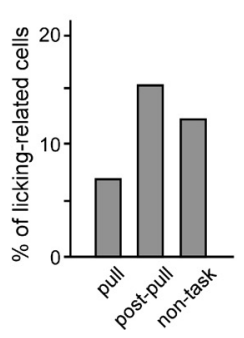

Figure 6. Characteristics of pull cells and post-pull cells. $A$, An example of a pull cell whose mean $\Delta F / F$ amplitude during the lever-pull period was proportional to the duration of the lever pull, $T_{\text {pull- }}$ The Spearman's rank correlation coefficient was $0.52\left(p<10^{-9}\right.$, Spearman's rank correlation coefficient test). $\boldsymbol{B}$, Percentage of pull cells, post-pull cells, and non-task-related cells whose mean activities during the lever-pull periods were significantly correlated with the durations of the lever pull, $T_{\text {pull }}(p<0.05$ by the Spearman's rank correlation test). Data were summarized from all 68 imaged fields (21 mice). C, Fluorescent traces of a post-pull cell that significantly responded to a $1 \mathrm{~s}$ vibration of the right forelimb were aligned with the start of successful lever pulls or the vibrations. Black lines and gray shading indicate mean \pm SEM. The lever trajectories and sensory stimulation time are shown below. $\boldsymbol{D}$, The percentage of cells that exhibited calcium transients that were significantly responsive to a $1 \mathrm{~s}$ vibration of the right forelimb. The mean transients $1 \mathrm{~s}$ before the stimulation and $1 \mathrm{~s}$ during the stimulation were compared using the Wilcoxon signed-rank test, $p<0.05$. $\boldsymbol{E}$, An example of a post-pull cell demonstrating calcium transients only in successful trials (and not in error trials). Black thick line indicates the mean trace. The lever trajectories in individual trials are overlaid in the bottom trace. $\boldsymbol{F}$, An example of a post-pull cell demonstrating calcium transients in both successful and error trials. $\boldsymbol{G}$, The percentages of lever return-related cells among the different cell types. $\boldsymbol{H}$, The percentage of licking-related cells among the different cell types.

68 imaged fields) exhibited mean activities during the lever-pull period that were significantly correlated with the durations of lever pulling (this includes both successful and error trials) (Fig. $6 A, B)$. Activity of post-pull cells after successful trials might in part reflect passive lever-return movement that was mediated by the mechanical force. Consistent with this idea, post-pull cells tended to respond to passive sensory stimuli that were applied to the right forelimb more frequently than pull cells when examined across 24 fields in seven anesthetized mice after the task performance (Fig. $6 C, D$ ). In fact, some post-pull cells did not exhibit calcium transients in error trials (Fig. $6 E$ ), which might also reflect reward signals. However, other post-pull cells exhibited calcium transients in both successful and error trials (Fig. 6F). The proportion of lever return-related cells across all 68 fields, defined as cells that exhibited significant activity after the end of the lever pull in error trials (when no mechanical force was provided), was larger in post-pull cells than pull cells (Fig. $6 G$ ). In addition, $15 \%$ of post-pull cells ( 9 of 59 in 12 fields of seven mice and when the infrared CCD camera clearly detected licking) exhibited significant activity during licking when there were no forelimb or body movements (Fig. $6 H$ ). Thus, the majority of pull cells increased their activity as the lever-pull duration increased, while post-pull cells were a collection of cells that displayed diverse activities in response to active and passive leverreturn movements, licking, sensory feedback signals, and reward signals.

\section{Functional clustering during the lever pull}

We next examined whether functional clustering occurred during the task performance. To quantify the time course of functional clustering, we introduced "geometric energy" at each time point, $E_{g}$, as an analogy of the energy function of a Hopfield network (Hopfield, 1982) and gravitational potential:

$$
E_{g}=-\sum_{j>i} J_{i j} F_{i} F_{j}, \quad J_{i j}=\frac{\frac{1}{r_{i j}}}{\sum_{n>m} \frac{1}{r_{m n}}},
$$

where $F_{i}$ and $F_{j}$ were normalized $\Delta F / F$ (from 0 to 1 ) of taskrelated cells $i$ and $j$, respectively, and $r_{i j}$ was their cellular distance in each imaged field. In this function, geometric weight, $J_{i j}$, was the inverse of the cellular distance so that the contribution of pairs of neighboring cells with high activity that were in the same time window was large. The energy of the activity of pairs without the geometric interaction $\hat{E}_{g},-\left\langle F_{i} F_{j}\right\rangle$, was also defined. $\Delta E_{g}, E_{g}-$ $\hat{E}_{g}$, represented the contribution of activity of clustered cells to the population activity. $\Delta E_{g}$ should be approximately zero when task-related cells are randomly distributed, and should also be negative when task-related cells are clustered (Fig. 7A). Using this equation, we calculated $\Delta E_{g}$ over the imaging session (Fig. $7 B$ ). In the field shown in Figure $4 A, \Delta E_{g}$ decreased during the task performance when the lever was being pulled (Fig. $7 B$ ). The mean $\Delta E_{g}$ across successful trials decreased at the start of the lever pull and was significantly negative during the lever-pull period when compared with the 50th lowest value (this is equivalent to a onesided $p$-value of $<0.05)$ of $\Delta E_{g}$ from 1000-time shuffled data in which the location of each cell was randomly assigned in this field (Fig. $7 C$ ). Then, after the end of the lever pull, the mean $\Delta E_{g}$ returned to statistically non-negative values. This return to nonnegative values was more rapid than that seen with the normalized population activity (Fig. 7C). Twenty-five (37\%) fields had at least one $50 \mathrm{~ms}$ time bin during the lever pull where $\Delta E_{g}$ was more negative than the 50th lowest value from the 1000-time shuffled data (Fig. $7 D, E)$. This rapid return of $\Delta E_{g}$ to baseline following the end of the lever pull was clearer when the inferred 
A
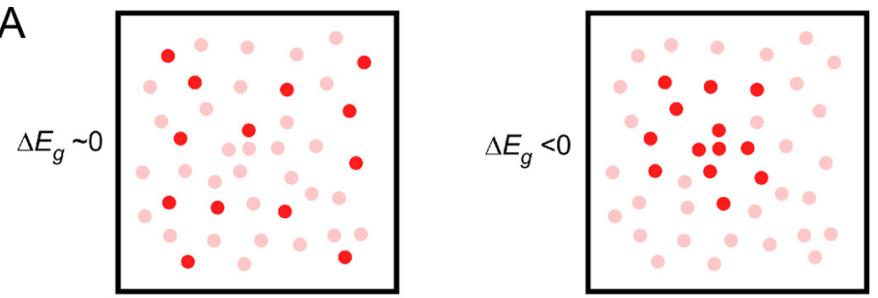

B

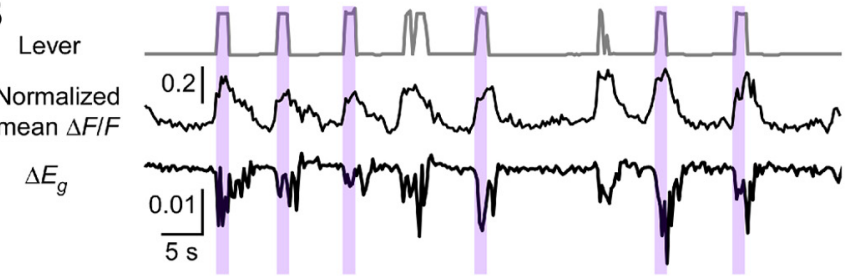

C
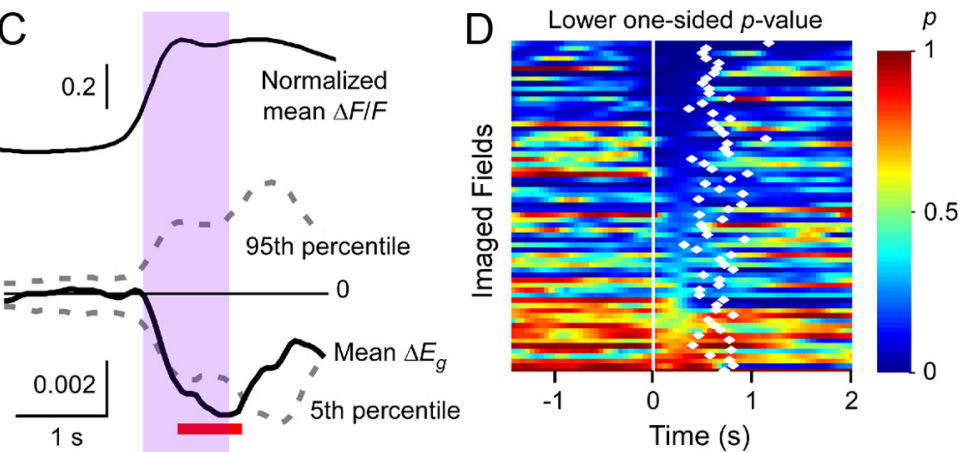

E

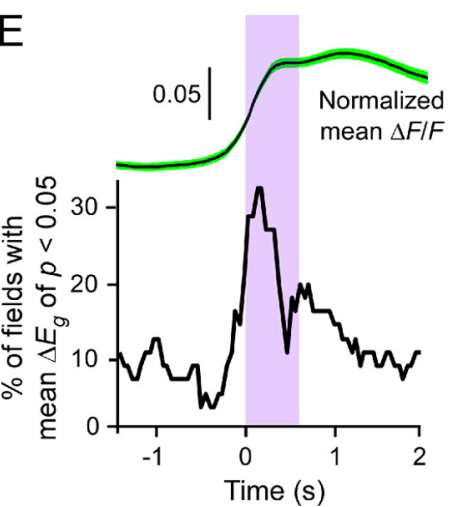

$\mathrm{F}$

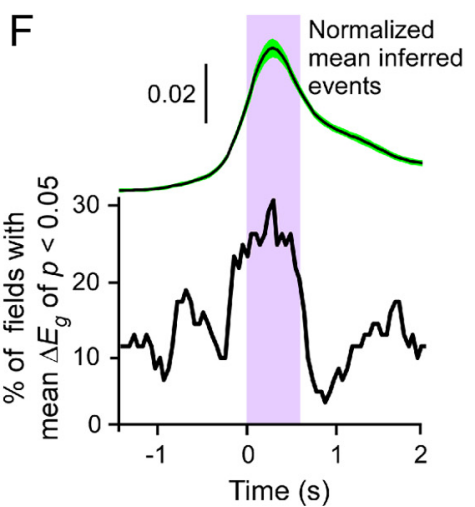

Figure 7. Time course of cluster formation and disruption. $\boldsymbol{A}$, Two schematic examples of the distribution of task-related cells. If task-related cells are randomly distributed (red circles), then $E_{q}$ is approximately equivalent to $\hat{E}_{q}$, which makes the value of $\Delta E_{q}$ approximately zero (left). If task-related cells are spatially clustered (red circles), then the mean distance between pairs is less than the mean distance between all pairs. In this case, $E_{g}$ is less than $\hat{E}_{g}$, and the value of $\Delta E_{g}$ is negative (right). $\boldsymbol{B}$, Example traces of the lever trajectory, the mean $F_{i}$ over all task-related cells (normalized $\Delta F / F$ ), and $\Delta E_{q}$ are aligned. The data were obtained from the fields shown in Figure $4 A$. Shaded boxes indicate successful lever pulls. $C$, The time courses of the mean normalized $\Delta F / F$ across successful trials and the mean $\Delta E_{g}$ of task-related cells across successful trials. Dotted lines indicate the mean $\Delta E_{g}$ of the lowest fifth and 95 th percentiles of $\Delta E_{g}$ from the shuffling data (in which the location of each cell was randomly assigned 1000 times). The red line indicates the time window when $\Delta E_{g}$ was less than the lowest fifth percentile of $\Delta E_{g}$ obtained from the shuffled data. The shaded box indicates the lever-pull duration averaged across successful trials. $D$, Pseudo-color plot of the lower one-sided $p$ values of $\Delta E_{g}$. The 66 fields that had $\geq 3$ task-related cells were vertically arranged according to their mean $p$ values at $250 \mathrm{~ms}$ after the start of the lever pull. The white line denotes the start of the lever pull. White diamonds denote the end of the lever pull. $\boldsymbol{E}$, The percentage of the imaged fields that showed significantly negative $\Delta E_{g}$ values (with lower one-sided $p$-values of $<0.05$ ) at each time point. The top trace shows the mean normalized $\Delta F / F$ averaged across the 66 fields (black line and green shading indicate mean \pm SEM). The shaded box indicates the mean lever-pull duration averaged across the 66 fields. $\boldsymbol{F}$, The percentage of the imaged fields that showed significantly negative $\Delta E_{g}$ values (with lower one-sided $p$-values of $<0.05$ ) at each time point when using the inferred events instead of $\Delta F / F$ for neuronal activities. The top trace shows the mean normalized inferred event averaged across the 66 fields (black line and green shading indicate mean \pm SEM).

event, and not $\Delta F / F$, was used to calculate $\Delta E_{g}$ (spike $\Delta E_{g}$ ) (Fig. $7 F$ ). This may be because the decay components of the calcium transients were removed. Thus, the functional clustering was temporally related to the lever-pull movement.

\section{Fine-scale functional cluster of pull cells}

The results from the geometric energy analyses suggest that neighboring pull cells tended to simultaneously increase their activity in individual trials. To further investigate this possibility, we defined a correlation of mean activities during the task-related period between pairs of taskrelated cells as a tCC. A high tCC value would, at least in part, reflect a high probability of synaptic connections (Ko et al., 2011). Furthermore, spatial dependencies of pairwise correlations are frequently observed in the cortex (Kerr et al., 2007; Dombeck et al., 2009; Komiyama et al., 2010; Rothschild et al., 2010; Hofer et al., 2011; Kampa et al., 2011). tCC decreased as cellular distance increased in both pairs of pull cells and pairs of post-pull cells pooled across 48 fields that included both $\geq 3$ pull cells and $\geq 3$ post-pull cells (11,536 pairs of pull cells: Pearson's correlation coefficient of $-0.17, p<10^{-15}$; Spearman's rank correlation coefficient test; 2151 pairs of post-pull cells: Pearson's correlation coefficient of $-0.12, p<$ $10^{-8}$; Spearman's rank correlation coefficient test). tCC, when measured at the same cellular distance of $<175 \mu \mathrm{m}$, was higher in pairs of pull cells than pairs of post-pull cells $(p<0.0001$ at $<100 \mu \mathrm{m}$ and $p<0.05$ at $100-175 \mu \mathrm{m}$; Wilcoxon rank sum test) (Fig. $8 A$ ). This result was consistent with the time course of $\Delta E_{g}$.

Next, we examined whether cell pairs included in a fine-scale $(<100 \mu \mathrm{m})$ spatial cluster of a multiple number of pull cells had higher tCC values than cell pairs outside the cluster. This would be expected because cells within a cluster would have stronger synaptic relationships than isolated pairs of cells (Song et al., 2005; Yoshimura et al., 2005). We counted the number of pull cells within variously sized circular areas without other types of cells and defined circles with more than four pull cells as "clusters." Then, the cluster with the maximum number of pull cells in each imaged field was defined as the "primary cluster" and the cells inside the primary cluster were defined as "primaryclustered cells." Pull cells that were not included in any clusters were defined as "nonclustered cells." Pull cells that were neither primary-clustered cells nor non- 
clustered cells were defined as "other clustered cells." Thus, we classified pull cells into three distinct groups (Table 2, Fig. $8 B-D)$. Thirty-six $(53 \%)$ of the total 68 fields had primary clusters with $8.3 \pm 3.1$ (5-16) cells. The diameters of the primary clusters were $67.8 \pm 16.2 \mu \mathrm{m}$ (Fig. $8 E$ ). tCC declined as cellular distance increased in both pairs of primary-clustered cells and pairs of nonclustered cells pooled across 30 fields that included primary clusters and $\geq 3$ nonclustered cells (1075 pairs of primary-clustered cells; Pearson's correlation coefficient of $-0.10, p<$ 0.0001 by the Spearman's rank correlation coefficient test; 1680 pairs of nonclustered cells: Pearson's correlation coefficient of $-0.14, p<10^{-15}$ by the Spearman's rank correlation coefficient test) (Fig. 8F, Table 2 ). As expected, tCC values between pairs of primary-clustered cells were significantly higher than pairs of nonclustered cells at a distance of $<75 \mu \mathrm{m}$ (Fig. $8 F ; p=$ 0.001 at $0-25 \mu \mathrm{m}$ and $p<0.001$ at $25-75$ $\mu \mathrm{m}$; Wilcoxon rank sum test). This result indicates that pairs of primary-clustered cells had stronger synaptic relationships than pairs of nonclustered cells at the same proximal distance. Twenty (80\%) of the 25 fields with significantly negative $\Delta E_{g}$ values during the lever pull had primary clusters. Thus, even though decreases in $\Delta E_{g}$ values did not necessarily indicate circular areas that only included pull cells, we considered primary-clustered cells to represent the components of fine-scale functional clusters.

\section{Clustered activity carried accurate lever movement trajectory information}

Because the activities of pull cells were well associated with lever-pull durations, we expected that pull cells might be important for processing of information about lever movement trajectory, and that the clustering of pull cells might be related to the amount of the information. Thus, we examined whether primary-clustered cells carried more accurate information regarding lever movement trajectory than nonclustered cells. To estimate the amount of information regarding lever movement, we applied a linear model (Wessberg et al., 2000) that used the combined activity of cells (see Materials and Methods). After linear model fitting of four-fifths of one-dimensional lever trajectory (training set), the remaining one-fifth lever trajectory (test set) was predicted (cross-validation method). In pull cells in Figure 8B, the prediction made from the ensemble activity of 15 primary-clustered cells was clearly more accurate than that of nine nonclustered cells in the same field (Fig. 9A). However, the comparison should be carried out only after the removal of any effects due to differences in the number of cells. To this end, we used neurondropping analyses in which individual neurons were randomly removed one by one (Wessberg et al., 2000). Linear model fittings
B RFA,15 primary-clustered cells, diameter $=61 \mu \mathrm{m}$.

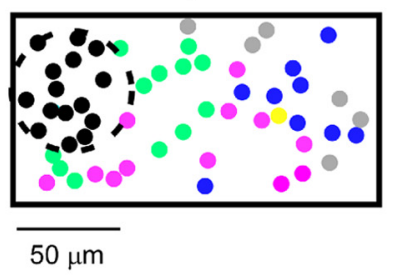

D

RFA, no primary cluster.
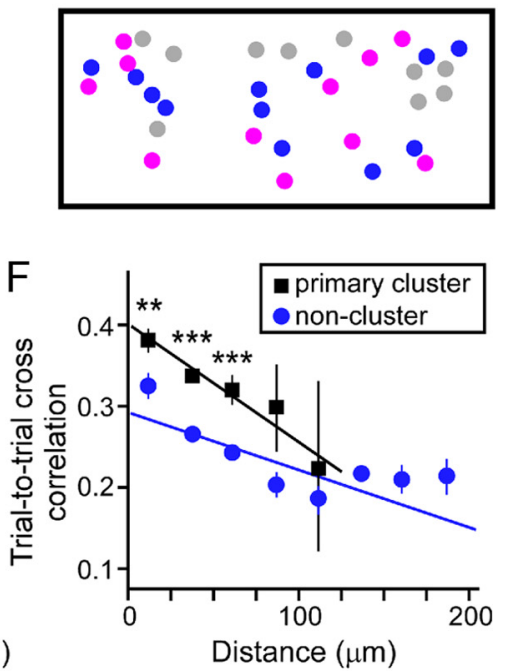

Figure 8. Spatial clusters of pull cells. $A, t C C s$ relative to cellular distances for 11,536 pairs of pull cells (cyan circles) and 2151 pairs of post-pull cells (magenta triangles) across 48 fields that included $\geq 3$ pull cells and $\geq 3$ post-pull cells ( 21 mice). Regression Fin the same colors. Cell pairs were grouped every $25 \mu \mathrm{m} .{ }^{* * *} p<0.0001$ and ${ }^{*} p<0.05$ by the Wilcoxon rank sum diameter of the primary cluster are indicated at the top of each field. Black, green, blue, magenta, yellow, and gray circles indicate primary-clustered pull cells, other clustered pull cells, nonclustered pull cells, post-pull cells, other task-related cells, and non-taskrelated cells, respectively. Dotted circles surround the primary clusters. $\boldsymbol{B}$ is the same field as in Figure $4 A$. Pull cells in $\boldsymbol{B}$ were used for the analyses in Figures $7, B$ and $C$, and $9, A$ and $B$. $E$, Histogram of the diameters of the primary clusters $(n=36$ fields that incer for 1075 pairs of primary-clustered cells (black cells $\left(16\right.$ mice). Regression lines are shown in the same colors as the cluster types. ${ }^{* *} p<0.001$ and ${ }^{* * *} p<0.0001$ by the Wilcoxon rank sum test. tCC was not significantly different at distances of $>75 \mu \mathrm{m}(p>0.05)$. Cell pairs were grouped every $25 \mu \mathrm{m}$.

and predictions made with the five-hold cross-validation methods were both repeatedly applied, and correlation coefficients $(c)$ between the overall predicted trajectory and the real trajectory were calculated (see Materials and Methods). $c$ from nine primary-clustered cells was larger than $c$ from nine nonclustered cells in Figure $8 B$ (dotted line in Fig. 9B). Furthermore, $c$ was significantly larger in primary-clustered cells than in nonclustered cells when the same number of cells (3-11 cells) were examined in each of the 30 imaged fields that included both a primary cluster and $\geq 3$ nonclustered cells ( $p=0.032$; Wilcoxon signed-rank test) (Fig. 9C). The mean $c$ of single cells in each field was also significantly larger for primary-clustered cells than for nonclustered cells (Fig. 9D; $p=0.020$; Wilcoxon signed-rank test, $n=30$ fields). These differences were also detected when a nonparametric fitting algorithm based on a bootstrap aggregation (TreeBagger implemented in MATLAB, the tree number of 100 and the minimum leaf size of 5; Huber et al., 2012), was used to predict the lever trajectory instead of the linear model fitting 
Table 2. The number of primary-clustered cells, other clustered cells, and nonclustered cells

\begin{tabular}{llll}
\hline & Primary-clustered cells & Other-clustered cells & Nonclustered cells \\
\hline 36 fields $^{*}$ (21 RFA, 15 CFA) & $8.3 \pm 3.2(8.3 \pm 2.6,8.3 \pm 3.9)$ & $8.3 \pm 8.0(9.2 \pm 7.5,7.5 \pm 8.7)$ & $8.3 \pm 5.8(8.0 \pm 6.1,8.7 \pm 5.4)$ \\
30 fields** $(18$ RFA, 12 CFA) & $8.4 \pm 3.2(8.2 \pm 2.4,8.6 \pm 4.3)$ & $7.5 \pm 5.9(8.3 \pm 5.9,6.3 \pm 6.1)$ & $9.7 \pm 5.3(9.1 \pm 6.0,10 \pm 4.0)$ \\
\hline
\end{tabular}

The number (mean \pm SD) across the corresponding fields is shown.

*Fields that included the primary cluster. **Fields with the primary cluster and more than two nonclustered cells used for Figures $8 F, 9 C, D$, and $10 A-C$.

\section{A}

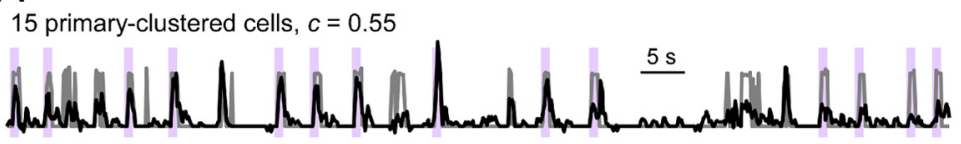

9 non-clustered cells, $c=0.40$

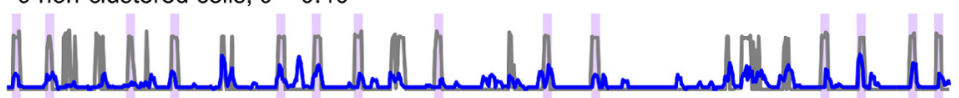

B
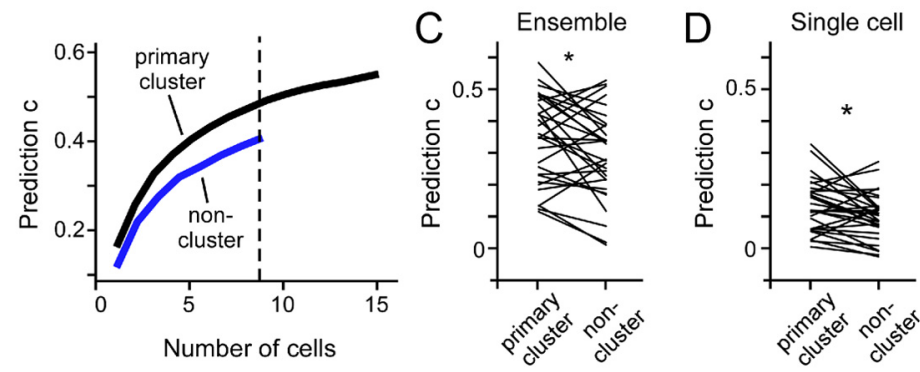

Figure 9. Prediction accuracy of the lever movement trajectory relative to neural ensemble activity of pull cells. $\boldsymbol{A}$, The linear model prediction of the lever trajectory (gray) from 15 primary-clustered cells (black) and nine nonclustered cells (blue) in the imaged field shown in Figure $8 B$. One of the test segments of the trajectory is shown. The correlation coefficients, $c$, between the predicted and real trajectories for this segment were 0.55 and 0.40 in the 15 primary-clustered and nine nonclustered cells, respectively. $\boldsymbol{B}$, Curves of cross-validation results were estimated by neuron-dropping analyses of the primary-clustered (black) and nonclustered (blue) cells in $\boldsymbol{A}$. The dotted line indicates a cell number of nine. $\boldsymbol{C}$, Comparison between c of primary-clustered cells and c of nonclustered cells for the same numbers of cells. Here, c values were calculated using whichever cell number was the smallest, the number of primary-clustered cells or the number of nonclustered cells in each imaged field. Each line indicates one imaged field. These analyses were performed from the 30 fields that included a primary cluster and $\geq 3$ nonclustered cells (16 mice). ${ }^{*} p=0.032$ by the Wilcoxon signed-rank test. $\boldsymbol{D}$, Line plots with one line for each imaged field going from the mean $c$ of single primary-clustered cells to the mean c of single nonclustered cells. These analyses were performed from the 30 fields indicated in $C$. ${ }^{*} p=0.020$ by the Wilcoxon signed-rank test.

(data not shown). These results indicate that the amount of lever movement information carried within the primary cluster was larger than outside the cluster when compared at both ensemble and single-cell activity levels.

\section{The high fidelity of activity in every trial was correlated with the amount of movement information}

The amount of lever movement information provided by cells might also be related to the fidelity for individual cells to be active in individual trials. We based this hypothesis on the idea that if a cell was active in every trial, it would then carry a large amount of lever trajectory information unless it was also frequently active during intertrial intervals. To determine this possibility, the ratio of successful trials that evoked a peak $\Delta F / F$ in the task-related period that was greater than three SD of $\Delta F / F$ over the entire imaging session was defined as active trial rate (ATR) for each cell. ATR was well correlated with the prediction correlation coefficient, $c$, of the lever trajectory for both primary-clustered cells and nonclustered cells that were pooled across the 30 imaged fields (251 primary-clustered cells: Pearson's correlation coefficient of $0.30, p<10^{-4}$ by the Spearman's rank correlation coefficient test; 292 nonclustered cells: Pearson's correlation coefficient of $0.28, p<10^{-4}$ by the Spearman's rank correlation coefficient test) (Fig. 10A). Consistent with $c$ being higher in primary-clustered cells than nonclustered cells $(0.131 \pm$ 0.104 vs $0.112 \pm 0.102, p=0.0090$; Wilcoxon rank sum test, $n=251$ primaryclustered cells and 292 nonclustered cells in the 30 fields), ATR was higher in primary-clustered cells than nonclustered cells $(0.435 \pm 0.18$ vs $0.380 \pm 0.17, p<$ 0.001; Wilcoxon rank sum test, $n=251$ primary-clustered cells and 292 nonclustered cells) (Fig. 10B). tCC values were also correlated with geometric mean ATR values in both pairs of primary-clustered cells and nonclustered cells (1075 pairs of primary-clustered cells: Pearson's correlation coefficient of $0.23, p<10^{-15}$ by the Spearman's rank correlation coefficient test; 1680 pairs of nonclustered cells: Pearson's correlation coefficient of $0.18, p<$ $10^{-10}$ by the Spearman's rank correlation coefficient test) (Fig. 10C). Thus, higher tCC and ATR values in primary-clustered cells might reflect underlying network properties that endow these cells with larger amounts of lever trajectory information than nonclustered cells.

By contrast, tCC values were not correlated with geometric mean ATR values in pairs of post-pull cells that were pooled across 48 fields that included both $\geq 3$ pull cells and $\geq 3$ post-pull cells (11,536 pairs of pull cells: Pearson's correlation coeffi-

cient of $0.33, p<10^{-7}$ by the Spearman's rank correlation coefficient test; 1680 pairs of post-pull cells, Pearson's correlation coefficient of $0.002, p=0.27$ by the Spearman's rank correlation coefficient test) (Fig. 10D). These data indicate that the relationship between tCC and ATR was dependent on the functional cell type.

\section{Discussion}

In this study, to reveal if, when, and how, fine-scale $(<100 \mu \mathrm{m}$ scale) functional clusters form and disappear during a voluntary forelimb movement, we developed a novel self-initiated leverpull task for head-restrained mice and performed two-photon calcium imaging of two mouse forelimb areas, the RFA and CFA. We found these areas in an unbiased fashion using OSM, and they were the same areas that had been identified by ICMS (Neafsey et al., 1986; Tennant et al., 2011). We detected the formation of functional clustering during lever pulls in $\sim 40 \%$ fields, and clusters of more than four pull cells in $\sim 50 \%$ fields. The lever trajectory was better predicted by the ensemble activity of primary-clustered cells than by that of nonclustered cells. Our results suggest a novel model of microcircuit activity dynamics 
whereby functional clusters are both formed and disrupted during voluntary behavior.

\section{Fine-scale functional clustering of pull cells}

We found functional clusters that consisted of more than four pull cells in a $\sim 70$ $\mu \mathrm{m}$ region in $53 \%$ of imaged fields. Finescale $(\sim 100 \mu \mathrm{m})$ clustering of both running- and grooming-related cells is detectable in the mouse motor cortex (Dombeck et al., 2009), whereas lickingand whisking-related cells in discrimination tasks do not show spatial segregation (Komiyama et al., 2010; Huber et al., 2012). Running and grooming use multiple parts of the body (Berridge and Whishaw, 1992; Rossignol et al., 2006). Licking and whisking are repetitive protraction and retraction movements that occur with high frequency (Travers et al., 1997; Gao et al., 2003). By contrast, the lever-pull movement in this study required the maintenance of grasping, pulling, and holding, which are all forelimb movements, during a certain period of time (Iwaniuk and Whishaw, 2000; Isomura et al., 2009; Kimura et al., 2012). In addition, the imaged fields were the motor forelimb areas. Thus, this is the first study to report the spatial distribution of cortical activities related to a well learned forelimb movement in the corresponding motor areas.

Although nearby units often respond together or have the same preference for a stimulus or movement, this was not always the case in our study. Even within a local area $(<100 \mu \mathrm{m}$ scale), where the connection probability between neighboring cells is relatively high $(\sim 0.1-0.2$, Holmgren et al., 2003; Song et al., 2005), there are probably multiple subnetworks (Yoshimura et al., 2005; Ko et al., 2011). In fact, we found that there were several specific types of cells in an imaged field of $\sim 200 \mu \mathrm{m} \times \sim 100 \mu \mathrm{m}$ size. Fine-scale $(\sim 70 \mu \mathrm{m})$ clusters that consist of more than four pull cells might represent only one of several strong subnetworks in a local area. In the primate, minicolumnar ( $~ 30 \mu \mathrm{m}$ width) structures that have the same preference for the movement direction have been proposed in the motor cortex (Georgopoulos et al., 2007). Therefore, the three-dimensional distribution of the fine-scale clusters and whether the fine-scale clusters are part of a columnar structure should all be further investigated by twophoton imaging in a broader three-dimensional area (Kampa et al., 2011).

\section{Spatiotemporal dynamics of clustering of microcircuit activity during voluntary movement}

We introduced the geometric energy function to demonstrate that cluster formations were significantly prominent during the lever-pulling periods in $37 \%$ of the imaged fields. Previous publications that examined the fine-scale distributions of taskrelated cells or sensory stimulus-responding cells did not examine the time courses of cluster dynamics during individual movements or sensory representations. The contribution of the geometric energy to the population activity, $\Delta E_{g}$, will also be a
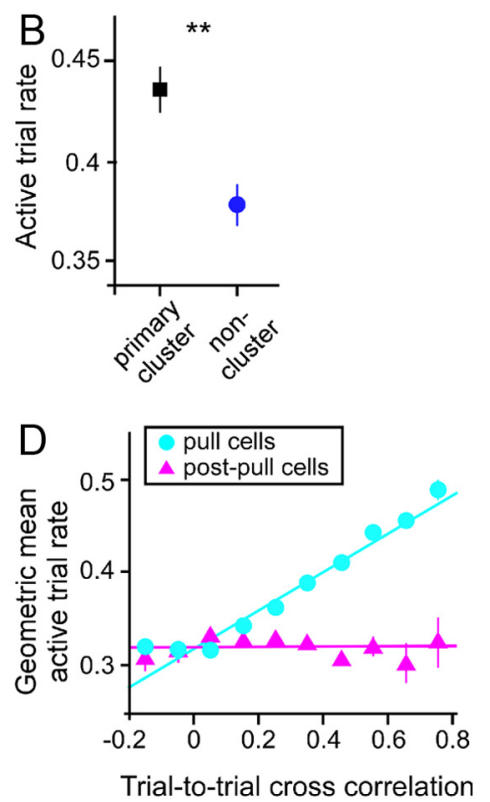

Trial-to-trial cross correlation

Figure 10. A high fidelity of activity accounts for the large amount of movement information carried by clustered pull cells. $A$, The correlation coefficient between the real and reconstructed lever trajectories relative to ATR values of single cells for 251 (black squares) and 292 nonclustered cells (blue circles) across the 30 fields, which included the primary

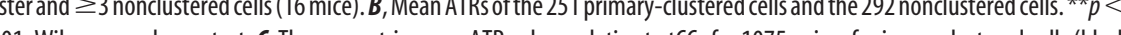
for 11,536 pairs of pull cells (cyan circles) and 2151 pairs of post-pull cells (magenta triangles) across 48 fields that included $\geq 3$ pull cells and $\geq 3$ post-pull cells (21 mice).

powerful parameter for estimating the temporal structure of functional clustered activities in three-dimensional distributions.

The functional cluster was not apparent before the start of the lever pull. However, in the primate motor cortex, preferred directions of reaching tend to be similar in nearby units during both preparation and movement periods (Stark et al., 2008). In that study, the preparation period started with the target presentations, and the activities in the preparation period were strongly related to the accurate movements that followed. Therefore, finescale clustering of relevant neurons might occur during preparation periods. Thus, in future studies, it will be important to investigate instructed-delay periods before movements to better understand which fine-scale distribution of neuronal activity represents movement preparation.

After the end of the lever pull, the functional clusters disappeared more rapidly than the population activities. The activities of the post-pull cells were related to the lever-return movement and licking, which did not require accuracy to receive the reward. Thus, the behavior after the end of the lever pull had more degrees of freedom (Todorov and Jordan, 2002) than the behavior before the end of the lever pull. Fine-scale functional clusters might only occur in periods that require accurate movements.

\section{Potential mechanisms to explain how neural ensembles of clustered cells carry a large amount of lever movement information}

The amount of lever movement information was well correlated with the ATR, and ATR values of pull cells within the primary cluster were higher than that outside the cluster. Furthermore, geometric mean ATR values were well correlated with tCCs, and tCC values were higher in primary-clustered cells than in nonclustered cells. This was not simply due to the proximal cellular distance, but rather to clustering of a multiple number of cells. 
Higher probabilities of reciprocal connections and/or stronger common synaptic inputs might cause clustered cells to be both more active (i.e., higher ATR) and more frequently covary in their activity (i.e., higher tCC) than nonclustered cells (Song et al., 2005; Yoshimura et al., 2005; Ko et al., 2011). If clustered cells in layer $2 / 3$ tend to innervate common neurons in layer 5 , then they may play a significant role in activating the layer 5 neurons that control the robust muscle activities necessary for lever pulling (Narayanan et al., 2005). Multiple whole-cell recordings may reveal what synaptic connections are related to high $\mathrm{tCC}$, high ATR, and high tCC-ATR correlations among clustered cells (de la Rocha et al., 2007; Ko et al., 2011).

In contrast to pull cells, post-pull cells did not demonstrate positive tCC-ATR correlations. When correlated inhibitory inputs are appropriately added, the positive tCC-ATR correlation should disappear (Renart et al., 2010). Inhibitory neuron activity is frequently detected in the motor cortex after the start of movements (Isomura et al., 2009; Kaufman et al., 2010). Introducing fluorescent proteins or optogenetic proteins expressed under specific promoters (Sohya et al., 2007; Fenno et al., 2011) should reveal whether the tCC-ATR correlation can be affected by activation of inhibitory neurons.

Motor learning increases the information about the movement that is encoded by neural ensemble activity in the motor cortex (Laubach et al., 2000; Paz and Vaadia, 2004). In the tadpole optic tectum, repeating visual stimuli induces clustering of cells with preferred-stimuli sensitivity (Podgorski et al., 2012). Thus, one possibility is that motor cortical cells that are related to the execution of a voluntary movement form a functional cluster during training. The firing of multiple nearby cells would enhance the firing of a given cell through recurrent connections so that long-term potentiation (LTP) of synaptic connections from long-range and/or local recurrent inputs may occur. This may result in an increase in the fidelity of the activity within the cluster. If LTP occurs among nearby cells and results in high activity, $\Delta E_{g}$ will be lower during the training session because the geometric weight, $J_{i j}$, is inversely proportional to the cellular distance. Long-term imaging of neural ensemble activity with genetically encoded calcium-sensitive proteins (Tian et al., 2009) could demonstrate when and how the cluster forms to carry more information during the learning process (Laubach et al., 2000).

\section{Microcircuit activity dynamics with cluster formation and disruption}

In summary, we propose that the spatial distribution of neuronal activities during task performance reflects the local circuit dynamics. As task-related neural ensembles evolve, the state space is constrained by strong, recurrent, and clustered excitatory networks. This results in the generation of an attractor-like state (Denève et al., 2007), which has low $\Delta E_{g}$ and accurately represents the well learned motor execution. Once the movement achieves its goal, functional clustering is rapidly disrupted. These temporal dynamics of local cortical activities with functional clustering may constitute a fundamental process for motor coordination. In this study we used mice, which allow for two-photon imaging to be combined with many other techniques that are more challenging in primates. Thus, the usage of head-restrained mice for forelimb movement tasks holds great promise for furthering the understanding of local cortical mechanisms that underlies the formation and representation of motor control.

\section{References}

Amirikian B, Georgopoulos AP (2003) Modular organization of directionally tuned cells in the motor cortex: is there a short-range order? Proc Natl Acad Sci U S A 100:12474-12479. CrossRef Medline

Asanuma H, Rosén I (1972) Topographical organization of cortical efferent zones projecting to distal forelimb muscles in the monkey. Exp Brain Res 14:243-256. CrossRef Medline

Ashe J, Georgopoulos AP (1994) Movement parameters and neural activity in motor cortex and area 5. Cereb Cortex 4:590-600. CrossRef Medline

Ayling OG, Harrison TC, Boyd JD, Goroshkov A, Murphy TH (2009) Automated light-based mapping of motor cortex by photoactivation of channelrhodopsin-2 transgenic mice. Nat Methods 6:219-224. CrossRef Medline

Ben-Shaul Y, Stark E, Asher I, Drori R, Nadasdy Z, Abeles M (2003) Dynamical organization of directional tuning in the primate premotor and primary motor cortex. J Neurophysiol 89:1136-1142. Medline

Berridge KC, Whishaw IQ (1992) Cortex, striatum and cerebellum: control of serial order in a grooming sequence. Exp Brain Res 90:275-290. Medline

de la Rocha J, Doiron B, Shea-Brown E, Josić K, Reyes A (2007) Correlation between neural spike trains increases with firing rate. Nature 448: 802-806. CrossRef Medline

Denève S, Duhamel JR, Pouget A (2007) Optimal sensorimotor integration in recurrent cortical networks: a neural implementation of Kalman filters. J Neurosci 27:5744-5756. CrossRef Medline

Dombeck DA, Khabbaz AN, Collman F, Adelman TL, Tank DW (2007) Imaging large-scale neural activity with cellular resolution in awake, mobile mice. Neuron 56:43-57. CrossRef Medline

Dombeck DA, Graziano MS, Tank DW (2009) Functional clustering of neurons in motor cortex determined by cellular resolution imaging in awake behaving mice. J Neurosci 29:13751-13760. CrossRef Medline

Fenno L, Yizhar O, Deisseroth K (2011) The development and application of optogenetics. Annu Rev Neurosci 34:389-412. CrossRef Medline

Gao P, Hattox AM, Jones LM, Keller A, Zeigler HP (2003) Whisker motor cortex ablation and whisker movement patterns. Somatosens Mot Res 20:191-198. CrossRef Medline

Georgopoulos AP, Merchant H, Naselaris T, Amirikian B (2007) Mapping of the preferred direction in the motor cortex. Proc Natl Acad Sci U S A 104:11068-11072. CrossRef Medline

Graziano MS, Taylor CS, Moore T (2002) Complex movements evoked by microstimulation of precentral cortex. Neuron 34:841-851. CrossRef Medline

Greenberg DS, Kerr JN (2009) Automated correction of fast motion artifacts for two-photon imaging of awake animals. J Neurosci Methods 176: 1-15. CrossRef Medline

Harvey CD, Coen P, Tank DW (2012) Choice-specific sequences in parietal cortex during a virtual-navigation decision task. Nature 484:62-68.

Hastie T, Tibshirani R, Friedman J (2009) The elements of statistical learning, Ed 2. New York: Springer.

Hira R, Honkura N, Noguchi J, Maruyama Y, Augustine GJ, Kasai H, Matsuzaki M (2009) Transcranial optogenetic stimulation for functional mapping of the motor cortex. J Neurosci Methods 179:258-263. CrossRef Medline

Hofer SB, Ko H, Pichler B, Vogelstein J, Ros H, Zeng H, Lein E, Lesica NA, Mrsic-Flogel TD (2011) Differential connectivity and response dynamics of excitatory and inhibitory neurons in visual cortex. Nat Neurosci 14:1045-1052. CrossRef Medline

Holmgren C, Harkany T, Svennenfors B, Zilberter Y (2003) Pyramidal cell communication within local networks in layer $2 / 3$ of rat neocortex. J Physiol 551:139-153. CrossRef Medline

Hopfield JJ (1982) Neural networks and physical systems with emergent collective computational abilities. Proc Natl Acad Sci U S A 79:25542558. CrossRef Medline

Huber D, Gutnisky DA, Peron S, O'Connor DH, Wiegert JS, Tian L, Oertner TG, Looger LL, Svoboda K (2012) Multiple dynamic representations in the motor cortex during sensorimotor learning. Nature 484:473-478. CrossRef Medline

Humphrey DR, Schmidt EM, Thompson WD (1970) Predicting measures of motor performance from multiple cortical spike trains. Science 170: 758-762. CrossRef Medline

Isomura Y, Harukuni R, Takekawa T, Aizawa H, Fukai T (2009) Microcir- 
cuitry coordination of cortical motor information in self-initiation of voluntary movements. Nat Neurosci 12:1586-1593. CrossRef Medline

Iwaniuk AN, Whishaw IQ (2000) On the origin of skilled forelimb movements. Trends Neurosci 23:372-376. CrossRef Medline

Kampa BM, Roth MM, Göbel W, Helmchen F (2011) Representation of visual scenes by local neuronal populations in layer $2 / 3$ of mouse visual cortex. Front Neural Circuits 5:18. Medline

Kaufman MT, Churchland MM, Santhanam G, Yu BM, Afshar A, Ryu SI, Shenoy KV (2010) Roles of monkey premotor neuron classes in movement preparation and execution. J Neurophysiol 104:799-810. CrossRef Medline

Kerr JND, Greenberg D, Helmchen F (2005) Imaging input and output of neocortical networks in vivo. Proc Natl Acad Sci U S A 102:14063-14068. CrossRef Medline

Kerr JND, de Kock CPJ, Greenberg DS, Bruno RM, Sakmann B, Helmchen F (2007) Spatial organization of neuronal population responses in layer 2/3 of rat barrel cortex. J Neurosci 27:13316-13328. CrossRef Medline

Kimura R, Saiki A, Fujiwara-Tsukamoto Y, Ohkubo F, Kitamura K, Matsuzaki M, Sakai Y, Isomura Y (2012) Reinforcing operandum: rapid and reliable learning of skilled forelimb movements by head-fixed rodents. J Neurophysiol 108:1781-1792. CrossRef Medline

Ko H, Hofer SB, Pichler B, Buchanan KA, Sjöström PJ, Mrsic-Flogel TD (2011) Functional specificity of local synaptic connections in neocortical networks. Nature 473:87-91. CrossRef Medline

Komiyama T, Sato TR, O'Connor DH, Zhang YX, Huber D, Hooks BM, Gabitto M, Svoboda K (2010) Learning-related fine-scale specificity imaged in motor cortex circuits of behaving mice. Nature 464:1182-1186. CrossRef Medline

Laubach M, Wessberg J, Nicolelis MAL (2000) Cortical ensemble activity increasingly predicts behaviour outcomes during learning of a motor task. Nature 405:567-571. CrossRef Medline

Lee D, Port NL, Kruse W, Georgopoulos AP (1998) Variability and correlated noise in the discharge of neurons in motor and parietal areas of the primate cortex. J Neurosci 18:1161-1170. Medline

Mukamel EA, Nimmerjahn A, Schnitzer MJ (2009) Automated analysis of cellular signals from large-scale calcium imaging data. Neuron 63:747760. CrossRef Medline

Narayanan NS, Kimchi EY, Laubach M (2005) Redundancy and synergy of neuronal ensembles in motor cortex. J Neurosci 25:4207-4216. CrossRef Medline

Neafsey EJ, Bold EL, Haas G, Hurley-Gius KM, Quirk G, Sievert CF, Terreberry RR (1986) The organization of the rat motor cortex: a microstimulation mapping study. Brain Res 396:77-96. CrossRef Medline

Paninski L, Fellows MR, Hatsopoulos NG, Donoghue JP (2004) Spatiotemporal tuning of motor cortical neurons for hand position and velocity. J Neurophysiol 91:515-532. Medline

Paz R, Vaadia E (2004) Learning-induced improvement in encoding and decoding of specific movement directions by neurons in the primary motor cortex. PLoS Biol 2:e45. CrossRef Medline

Podgorski K, Dunfield D, Haas K (2012) Functional clustering drives encoding improvement in a developing brain network during awake visual learning. PLoS Biol 10:e1001236. CrossRef Medline

Renart A, de la Rocha J, Bartho P, Hollender L, Parga N, Reyes A, Harris KD (2010) The asynchronous state in cortical circuits. Science 327:587-590. CrossRef Medline
Rossignol S, Dubuc R, Gossard JP (2006) Dynamic sensorimotor interactions in locomotion. Physiol Rev 86:89-154. CrossRef Medline

Rothschild G, Nelken I, Mizrahi A (2010) Functional organization and population dynamics in the mouse primary auditory cortex. Nat Neurosci 13:353-360. CrossRef Medline

Smith WS, Fetz EE (2009) Synaptic interactions between forelimb-related motor cortex neurons in behaving primates. J Neurophysiol 102: 1026-1039. CrossRef Medline

Sohya K, Kameyama K, Yanagawa Y, Obata K, Tsumoto T (2007) GABAergic neurons are less selective to stimulus orientation than excitatory neurons in layer II/III of visual cortex, as revealed by in vivo functional $\mathrm{Ca}^{2+}$ imaging in transgenic mice. J Neurosci 27:2145-2149. CrossRef Medline

Song S, Sjöström PJ, Reigl M, Nelson S, Chklovskii DB (2005) Highly nonrandom features of synaptic connectivity in local cortical circuits. PLoS Biol 3:e68. CrossRef Medline

Stark E, Globerson A, Asher I, Abeles M (2008) Correlations between groups of premotor neurons carry information about prehension. J Neurosci 28:10618-10630. CrossRef Medline

Stark E, Drori R, Abeles M (2009) Motor cortical activity related to movement kinematics exhibits local spatial organization. Cortex 45:418-431. CrossRef Medline

Tennant KA, Adkins DL, Donlan NA, Asay AL, Thomas N, Kleim JA, Jones TA (2011) The organization of the forelimb representation of the C57BL/6 mouse motor cortex as defined by intracortical microstimulation and cytoarchitecture. Cereb Cortex 21:865-876. CrossRef Medline

Thévenaz P, Ruttimann UE, Unser M (1998) A pyramid approach to subpixel registration based on intensity. IEEE Trans Image Process 7:27-41. CrossRef Medline

Tian L, Hires SA, Mao T, Huber D, Chiappe ME, Chalasani SH, Petreanu L, Akerboom J, McKinney SA, Schreiter ER, Bargmann CI, Jayaraman V, Svoboda K, Looger LL (2009) Imaging neural activity in worms, flies and mice with improved GCaMP calcium indicators. Nat Methods 6:875881. CrossRef Medline

Todorov E, Jordan MI (2002) Optimal feedback control as a theory of motor coordination. Nat Neurosci 5:1226-1235. CrossRef Medline

Tohmi M, Takahashi K, Kubota Y, Hishida R, Shibuki K (2009) Transcranial flavoprotein fluorescence imaging of mouse cortical activity and plasticity. J Neurochem 109:3-9. CrossRef Medline

Travers JB, Dinardo LA, Karimnamazi H (1997) Motor and premotor mechanisms of licking. Neurosci Biobehav Rev 21:631-647. CrossRef Medline

Wang H, Peca J, Matsuzaki M, Matsuzaki K, Noguchi J, Qiu L, Wang D, Zhang F, Boyden E, Deisseroth K, Kasai H, Hall WC, Feng G, Augustine GJ (2007) High-speed mapping of synaptic connectivity using photostimulation in Channelrhodopsin-2 transgenic mice. Proc Natl Acad Sci U S A 104:8143-8148. CrossRef Medline

Wessberg J, Stambaugh CR, Kralik JD, Beck PD, Laubach M, Chapin JK, Kim J, Biggs SJ, Srinivasan MA, Nicolelis MAL (2000) Real-time prediction of hand trajectory by ensembles of cortical neurons in primates. Nature 408:361-365. CrossRef Medline

Yoshimura Y, Dantzker JLM, Callaway EM (2005) Excitatory cortical neurons form fine-scale functional networks. Nature 433:868-873. CrossRef Medline 